\title{
Quo Vadis Micro-Electro-Mechanical Systems for the Study of Heterogeneous Catalysts Inside the Electron Microscope?
}

\author{
Maxime Boniface $^{1,2} \cdot$ Milivoj Plodinec $^{1} \cdot$ Robert Schlögl $^{1,2} \cdot$ Thomas Lunkenbein $^{1}$
}

Accepted: 4 November 2020 / Published online: 17 November 2020

(c) The Author(s) 2020

\begin{abstract}
During the last decade, modern micro-electro-mechanical systems (MEMS) technology has been used to create cells that can act as catalytic nanoreactors and fit into the sample holders of transmission electron microscopes. These nanoreactors can maintain atmospheric or higher pressures inside the cells as they seal gases or liquids from the vacuum of the TEM column and can reach temperatures exceeding $1000^{\circ} \mathrm{C}$. This has led to a paradigm shift in electron microscopy, which facilitates the local characterization of structural and morphological changes of solid catalysts under working conditions. In this review, we outline the development of state-of-the-art nanoreactor setups that are commercially available and are currently applied to study catalytic reactions in situ or operando in gaseous or liquid environments. We also discuss challenges that are associated with the use of environmental cells. In catalysis studies, one of the major challenge is the interpretation of the results while considering the discrepancies in kinetics between MEMS based gas cells and fixed bed reactors, the interactions of the electron beam with the sample, as well as support effects. Finally, we critically analyze the general role of MEMS based nanoreactors in electron microscopy and catalysis communities and present possible future directions.
\end{abstract}

Keywords MEMS $\cdot$ TEM $\cdot$ In situ $\cdot$ Operando $\cdot$ Characterization $\cdot$ Catalysis

\section{Introduction}

Micro-electro-mechanical systems (MEMS) refer to devices that have characteristic dimensions in the micrometer regime. They combine electrical and mechanical components on a single chip and are fabricated by integrated circuit batch-processing technologies. In recent years the level of miniaturization and integration of MEMS technology has been used to scale down laboratory systems such as sensors or heaters to length-scales that are compatible with electron microscopes and allows for their integration. This has enabled a new era of in situ (scanning) transmission electron

Dedicated to Prof. Dr. Norbert Kruse on the occasion of his 70th birthday.

Thomas Lunkenbein

lunkenbein@fhi-berlin.mpg.de

1 Department of Inorganic Chemistry, Fritz-Haber-Institut der Max-Planck-Gesellschaft, 14195 Berlin, Germany

2 Department of Heterogeneous Reactions, Max Planck Institute for Chemical Energy Conversion, 45413 Mülheim a.d. Ruhr, Germany microscopy ((S)TEM), which is a reference technique for the spatially-resolved structural and chemical analysis of solids [1-4].

These novel lab-on-a-chip systems enable live imaging of structural and morphological changes of solids from the microscale down to the atomic scale under various external stimuli, such as heat, mechanical stress or electrical bias, which can be also combined with gaseous or liquid environments $[5,6]$. These functions are embarked on small chips that fit into the tips of TEM sample holders. Using off-theshelf holders combined with MEMS-based nanoreactors, any standard (S)TEM instrument can now be transformed into an in situ setup for the investigation of catalytic materials in realistic working conditions. Gases and liquids can run through these devices, in which pressures surmounting 1000 mbar can be achieved. As opposed to designing the entire instrument around the desired in situ experiment, as it has been done with differentially pumped environmental TEM (ETEM) setups, a simple holder exchange is sufficient to switch between different in situ experiments. As such, MEMS-based technology has crucially enhanced the experimental flexibility, performance and accessibility of in situ TEM systems. These advances have contributed to a 
significant growth of scientific contributions in the field of in situ TEM for catalysis, as evidenced by the large number of review articles that have been published recently [7-14]. A chronological summary of the combined MEMS and in situ TEM developments can be found in Fig. 1.

Besides their prominent use for in situ TEM measurements, MEMS devices are part of a variety of different applications ranging from neuroscience [15] to biosensors [16] and scientific instrumentation [17]. MEMS technology has also been utilized for the design of miniature catalytic systems [18] such as proton exchange membrane fuel cells
(PEMFCs) [19], methanol reformers [20] and sensors [21]. Examples of such systems can be found in Fig. 2. We believe that the contributions of MEMS to the entire field of heterogeneous catalysis warrant a review of their own.

Here, we specifically focus on the contributions of MEMS-based nanoreactors to the TEM investigation of heterogeneous catalysts in a reactive environment. These nanoreactors have been used to probe the chemical dynamics of heterogeneous catalysts in real time, either in situ i.e. in a controlled environment such as a solution or reaction gas mixture, or operando, when the catalytic conversion is
Fig. 1 Chronology of major MEMS and in situ TEM developments

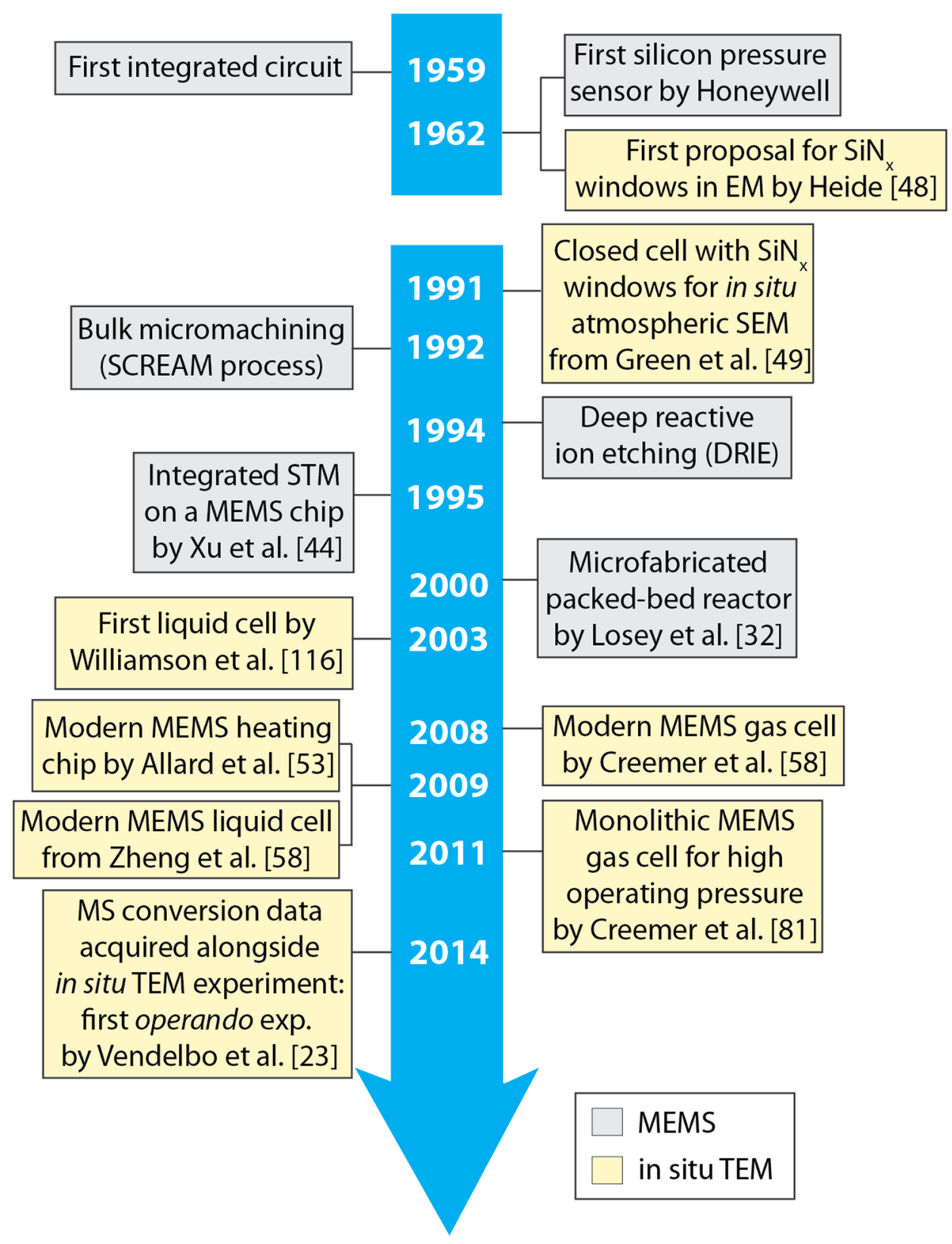



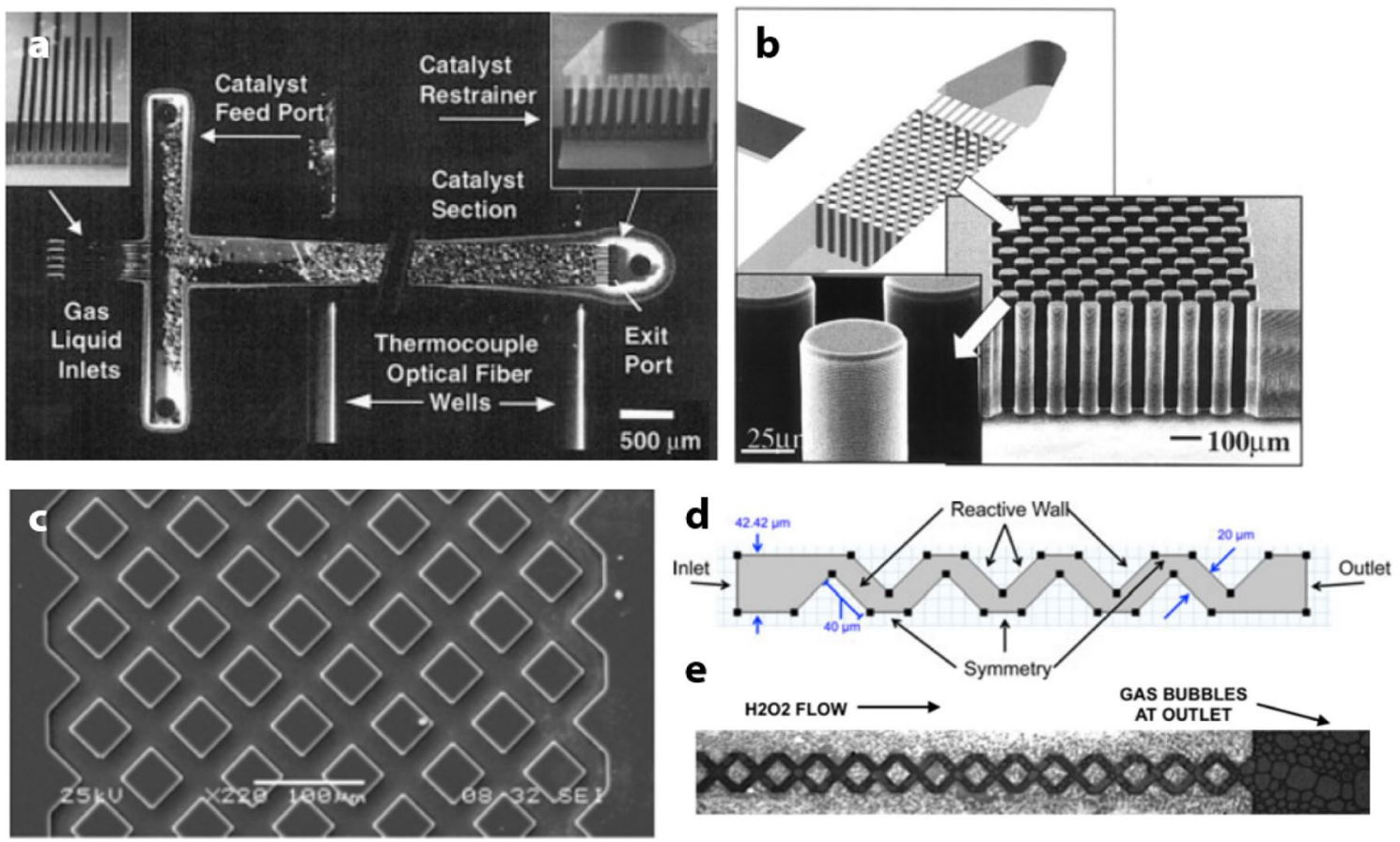

Fig. 2 Examples of applications of MEMS based devices in heterogeneous catalysis. a Photomicrograph of a packed bed miniaturized reactor with an active carbon catalyst. The inlet openings are $30 \mu \mathrm{m}$ wide and $300 \mu \mathrm{m}$ deep. b Microfabricated catalyst packing manufactured by deep reaction ion-edging (DRIE). c-e Illustration of a MEMS-based microreactor for a $\mathrm{H}_{2} \mathrm{O}_{2}$ monopropellant micropropul-

additionally measured alongside TEM observations [22-26]. The operando approach can help establish detailed local structure-property relationships. Such insights will enable novel rational catalyst design strategies that are more advanced compared to current catalyst development workflows which usually consist of ex situ characterization and empirical optimization. Rational design will result in more efficient catalysts. Insights into the live operation of catalytic materials is also relevant to industry, as over $90 \%$ of commercially available chemicals interact, at least in one production step with the surface of a heterogeneous catalyst [27]. Furthermore, liquid cells have also enabled seminal in situ works, especially in the investigation of electrocatalysis [28, $29]$ and the synthesis of nanomaterials [30, 31].

In this paper, we will review the evolution of MEMSbased TEM instrumentation for gas and liquid phase (electro)catalysis. In addition, we will critically discuss existing challenges of such in situ TEM experiments. As in situ TEM applications have already been the subject of several reviews [7-14], we will focus on the design and materials of MEMS themselves. We discuss the relevance of the kinetics in gas cells, with regard to the discrepancies between these nanoreactors and fixed bed reactors (FBR). An analysis of the role of the $\mathrm{SiN}_{\mathrm{x}}$ windows is also proposed, which ranges from its role as a catalyst support in some in situ experiments, to

sion system. c SEM micrograph that shows scaffolds of sample pillars obtained from DRIE etching. The pillars are $20 \mu \mathrm{m}$ wide and $5 \mu \mathrm{m}$ high. d Schematic diagram of the reactor geometry. e Imaging of $\mathrm{H}_{2} \mathrm{O}_{2}$ decomposition through a single row of catalytic pillars. Reproduced with permissions from [32-34]

their impact on the quality of TEM observations. Finally, we present suggestions for the future of MEMS based systems for the spatially-resolved study of heterogeneous catalysts.

\section{Early Contributions of MEMS to TEM Instrumentation}

The most emblematic use of MEMS devices for the characterization of materials can be found in their debut with in situ measurements of the mechanical properties of materials used in the fabrication of MEMS devices, such as silicon. Pioneering work in the second half of the 1990s and early 2000s [35-37] focused on the on-chip fabrication of actuators capable of nanometer-scale movements by applying controlled forces in the order of millinewton $(\mathrm{mN})$. Such systems could be operated inside the chamber of a scanning electron microscope (SEM). These integrated actuators were further developed and scaled down to fit into the tip of a typical TEM holder. This enabled the investigation of mechanical properties of nano-objects such as thin films [38, 39], nanowires [40] and single carbon nanotubes [41, 42]. Other devices reached nanonewton $(\mathrm{nN})$ sensitivity, which was sufficiently low to perform atomic force microscopy (AFM) inside the TEM column and further illustrates the 
polyvalence of MEMS devices [43] for the characterization of materials. This AFM device followed earlier achievements [44, 45], such as the development of a scanning tunneling microscope (STM) embarked on a MEMS chip designed to fit in a TEM. This concept was introduced as early as 1995 [46].

Alongside these novel characterization capabilities powered by micromechanical functions, MEMS fabrication technology has also been used to miniaturize electrical systems in order to apply biases to individual nanostructures. The first example of such an application was the design of an on-chip nanocalorimeter [47] which could be mounted onto a TEM holder after calorimetric measurements had been conducted outside the microscope. This study can be also considered as the re-introduction of electron-transparent silicon nitride $\left(\mathrm{SiN}_{\mathrm{x}}\right)$ windows as specimen supports, which was initially proposed in 1962 [48]. To date, such $\mathrm{SiN}_{\mathrm{x}}$ windows $[49,50]$ are still the cornerstones of MEMS-based in situ TEM technology. Later on, this microcalorimetric setup was augmented into a complete in situ experiment using external electrical contacts that run through the holder to the chip, which allows the efficient operation of MEMS-based systems inside the column of the TEM. This device can be considered the first modern in situ TEM holder [51].

Subsequently, MEMS-based microheaters [52, 53] were developed that showed superior performances compared to classical TEM heating stages [54]. Classical TEM heating holders suffer from high spatial drift and lack the ability for rapid heating and cooling. A design addressing these disadvantages was put forward by Allard et al. [53], who demonstrated the ability to cycle from room temperature (RT) to $1000{ }^{\circ} \mathrm{C}$ in $1 \mathrm{~ms}$. The drift stayed sufficiently low to find areas of interest and to achieve sub-Angström resolution after thermal relaxation. In this design, the $\mathrm{SiN}_{\mathrm{x}}$ membrane

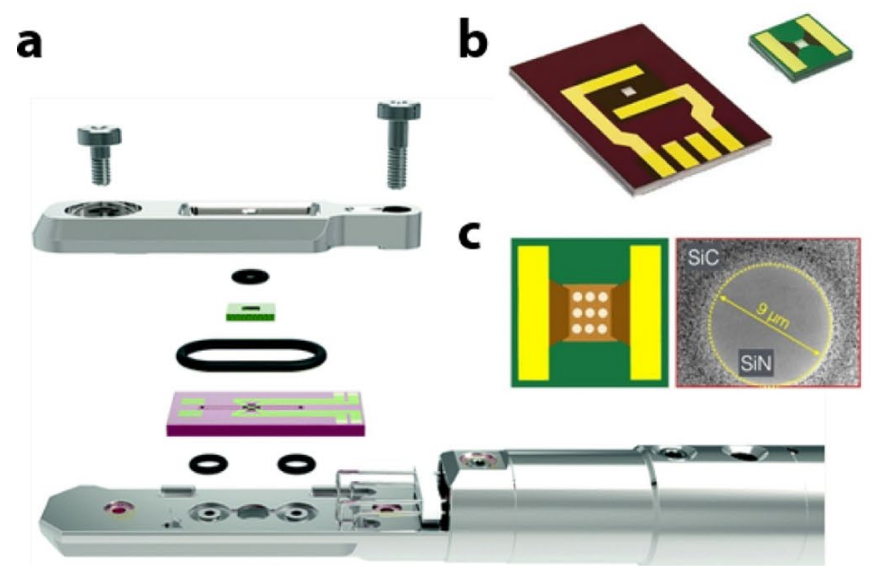

Fig. 3 Design of a modern MEMS based in situ TEM gas cell. a Side view of the assembly of the «sandwich» design. Example from DENSsolutions. b MEMS chips from Protochips. c View of the $\mathrm{SiN}_{\mathrm{x}}$ is the heating surface and is in direct contact with the sample. Its small surface area makes fast heating and cooling rates possible. Finally, the membrane is patterned with holes and overlaid with a holey carbon film to ensure the background for TEM observations is comparable to a typical holey carbon coated TEM grid.

\section{Gas Cells}

Similar high performance MEMS-based heating chips were soon used in a closed-cell (also referred to as "gas cells" or "nanoreactors") design [55]. These designs were inspired by earlier pioneering works from Giorgio et al. [56] and Konishi et al. [57] who used electron transparent carbon windows. An illustration of a modern in situ TEM gas cell can be found in Fig. 3. In this closed cell array the specimen and its gaseous environment are isolated from the vacuum of the TEM column. In two seminal papers, Creemer et al. $[58,59]$ first proposed such a nanoreactor. It consists of two facing silicon chips, each with a central hole of $1 \mathrm{~mm}^{2}$ and is covered by a $1.2 \mu \mathrm{m}$ thick membrane of $\mathrm{SiN}_{\mathrm{x}}$ that has a smaller central area with a thickness of $10 \mathrm{~nm}$. The opposing membranes form the top and bottom of a shallow gas-flow channel (Fig. 3b). The minimum height of the channel is $4 \mu \mathrm{m}$, determined by disc-shaped spacers integrated in one of the membranes. Both ends of the channel are connected through the holder to microfluidic tubings, which allows the flow of pressurized gases. The pressure inside the cell is controlled by inlet and outlet pressure controllers and needle valves. The authors highlighted that $\operatorname{SiN}_{\mathrm{x}}$ windows should be amorphous to avoid added electron diffraction contrast [60], which would be detrimental to TEM observations. This

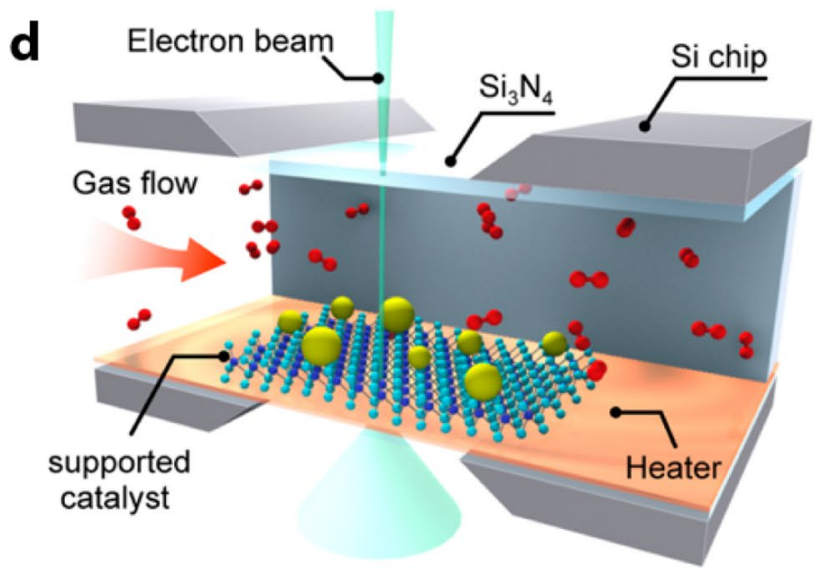

membrane covering a hole in the SiC ceramic. d Schematic view of a gas MEMS nanoreactor in operation. Reproduced with permissions from $[26,85]$ and [86] 
nanoreactor marked a clear turn in approach for environmental TEM study [26].

Aperture-based ETEMs [54, 61-66], where differential pumping systems are used to confine gasses near the sample, can offer better resolutions and contrasts as they do not deal with the additional scattering brought on by the silicon nitride windows. This makes differentially pumped ETEM superior for the imaging of light element materials, such as graphene [67] or light organic molecules [68]. A review of atomically resolved in situ studies powered by differentially pumped ETEM investigations has recently been published by Boyes et al. [65]. However, these microscopes only work at low operating pressures, in the $10^{2}-10^{3} \mathrm{~Pa}$ range [67], corresponding to a gas path length of $7 \mathrm{~mm}$. At higher pressures, the background scattering will be too high to achieve satisfactory TEM observations. It is worth noting here that the scattering cross-section does not depend only on pressure, but on accelerating voltage and on the atomic number of the gas as well $[67,69]$.

Differentially pumped ETEM experiments come with several drawbacks. Besides the question of cost, as they require a wholly dedicated instrument-whereas any electron microscopy laboratory can potentially equip itself with a nanoreactor holder-differentially pumped ETEM setups do not allow for the control of the gas flow, as they use a large quantity of gas around the sample. Controlling the inlet gas flow is crucial to quantitative TEM catalysis experiments as it will impact the kinetics of the reaction of interest, as we discuss further on. Furthermore, closed-cell designs can withstand atmospheric pressure, effectively bridging the existing "pressure gap" between differentially pumped ETEM experiments and industrial reactors. This is critical to the relevance of in situ results to real applications in catalysis research. The properties of nanomaterials depend strongly on their structure and morphology [70-73], which are themselves dependent on experimental conditions [74, 75]. In the gas phase, activity depends on partial pressures, which in turn affect the Gibbs free energy of the system and can lead to different dynamical behavior of the catalysts. To date, it is still unclear how the structural response of nanomaterials at lower pressures relates to their dynamic behavior at ambient pressure conditions. Finally, STEM operation in ETEMs is limited, as the differential pumping apertures below the specimen shadows most of the high-angle annular dark-field (HAADF) detector. Thus, heavy elements can be imaged with superior contrast inside MEMS-based nanoreactors, which is pivotal to the study of metallic heterogeneous catalysts.

Allard et al. [55] reported atomic column resolution in $\mathrm{Rh}$ nanoparticles using $30 \mathrm{~nm}$ thick windows. It is a considerable improvement over the $0.2 \mathrm{~nm} \mathrm{Cu}(200)$ lattice spacing resolution obtained with the initial gas cell design from Creemer et al. [58], which in addition used windows only
$10 \mathrm{~nm}$ thick. De Jonge et al. [76] demonstrated in another similar MEMS-based design a $0.4 \mathrm{~nm}$ STEM resolution through $50 \mathrm{~nm}$ thick $\mathrm{SiN}_{\mathrm{x}}$ windows and a $360 \mu \mathrm{m}$ thick gas layer. Atomic resolution STEM imaging was also demonstrated for $\mathrm{Pd}[77,78]$ and $\mathrm{Pt}_{3} \mathrm{Co}$ [79] nanoparticles deposited on $30 \mathrm{~nm}$ thick windows. These examples show that high resolution imaging is achievable with MEMS-based nanoreactors.

Alternative nanoreactor designs, which are not MEMSbased, have been proposed by Kawasaki et al. [80] and Yaguchi et al. [69]. Creemer et al. [81] introduced the monolithic cell, departing from the sandwich design the same authors have pioneered. Mehraeen et al. [82] proposed localized laser heating as an alternative to the microheater of existing in situ MEMS chips, with the aim to selectively heat the specimen and minimize heat conduction inside the cell. Overall the sandwich design with two MEMS chips, including one chip that integrates the microheater, was popularized and made into the commercial products that are currently offered by Hummingbird, DENSsolutions, and Protochips. The accessibility of gas cell TEM holders has made them increasingly ubiquitous for the characterization of heterogeneous catalysts $[9,25]$. The technique has garnered attention from all sub-fields of catalysis $[8,9,26]$.

Custom designs have also been published and although they are similar to commercial systems, some of them can be operated at higher pressures than the nominal atmospheric conditions of standard systems [81, 83, 84]. This is discussed in the next section.

\section{Gas Cells-Towards Higher Operating Pressures}

Although MEMS-based nanoreactors already improve the achievable operating pressure by almost two orders of magnitude compared to differentially pumped ETEM setups, even higher pressures are required to study certain catalytic processes under realistic operating conditions. Ethylene oxidation and ammonia synthesis for instance are done above 50 bars which is out of reach of typical nanoreactors [87].

As a result quasi in situ workflows have been proposed to bridge that pressure gap $[88,89]$. A quasi in situ experiment goes as follows: (i) an area of interest is selected on a TEM grid for identical location imaging before the catalytic reaction. (ii) the grid is transferred under controlled atmosphere to a dedicated high pressure reactor where catalytic conversion can be measured by mass spectrometry [88]. (iii) It can then be transferred back to the TEM with the same protocol, and the location previously chosen can then be investigated for morphological and structural changes induced by catalysis. Detrimental interactions between the electron beam, the reactant species, and the 
catalyst sample can therefore be avoided. However, quasi in situ protocols (i) do not directly capture the dynamics of the catalytic process, (ii) do not allow for a direct correlation of catalytic conversion measurements with TEM observations as they are acquired separately and (iii) involve the characterization of catalysts in vacuum rather than in realistic operating conditions, which can influence a catalysts' structure [74].

Researchers have proposed novel MEMS-based designs that have been reported to reach pressures exceeding 1 bar at high temperatures. These designs have improved on the mechanical properties of $\mathrm{SiN}_{\mathrm{x}}$ windows by tuning their geometries or have featured monolithic cells, which are fabricated on a single chip. In the first case, it was shown that lowering the lateral dimensions of windows and eliminating sharp corners led to more robust cells. For instance, it has been demonstrated that small circular $15 \mathrm{~nm}$ windows could sustain up to 4 bars, although the authors do not report any operation above $240{ }^{\circ} \mathrm{C}[83,90]$. This is significant as thermal expansion further stresses the electron transparent windows [91], hence operation at low temperatures does not guarantee stability at higher temperatures. Thinner windows could surprisingly also offer superior mechanical properties to sustain pressures differences compared to thicker ones. This difference was attributed to a lower number of critical defects, which can act as predetermined breaking points at smaller volumes. All MEMS-based designs, including the current commercial ones, adopted smaller circular windows etched in a larger central $\mathrm{SiN}_{\mathrm{x}}$ membrane, as illustrated in Fig. 4c.

In the case of monolithic cells, microreactors are entirely fabricated from batch processing techniques on a single chip, rather than from the assembly of two chips. In the original paper [81], the cell features pillars that hold together the top and bottom $\mathrm{SiN}_{\mathrm{x}}$ membranes, thereby increasing their strength and rigidity and allowing reliable operation up to 14 bars at $800^{\circ} \mathrm{C}$. A similar design later demonstrated operational stability at 10 bars and $650{ }^{\circ} \mathrm{C}$ [84]. It is worth noting that sample preparation could be limiting with monolithic cells. Since the inside of the cell cannot readily be accessed, samples can only be introduced dispersed in a solution through the microfluidics inlet.

It is worth noting that at such high operating pressures the electron beam travels through a significantly denser gas atmosphere than under atmospheric conditions. This can be expressed in terms of a much longer gas path length $[69,81]$. This would result in a higher scattering background for (S) TEM imaging, which would be detrimental to the signal-tonoise-ratio (SNR) and limit imaging resolution. More beaminduced chemistry is also to be expected, in the form of a higher amount of radiolysis products as discussed later on in the section on liquid cells. To our knowledge, these high pressure designs have to date not been used to investigate catalytic processes at pressures above 1 bar. We emphasize that proofs of concepts are available. However, they are likely to stay on that stage baring commercialization.
Fig. 4 Illustration of the monolithic high-pressure cell. a Schematic of the monolithic cell. All functionality is integrated on a single chip, as opposed to the popular «sandwich» design that uses two chips. $\mathrm{SiN}_{\mathrm{x}}$ pillars separate the top and bottom of the channel. This design can withstand pressures above 10 bars. b Photograph of two complete nanoreactors under different angles. c Optical image of the central membrane of the nanoreactor featuring a number of aligned $\mathrm{SiN}_{\mathrm{x}}$ transparent windows that are 2 to $5 \mu \mathrm{m}$ thick. The inset shows the glowing of the chip at $800^{\circ} \mathrm{C}$. d Stress distribution within the central $\mathrm{SiN}_{\mathrm{x}}$ membrane. Reproduced with permissions from [81] and [90]
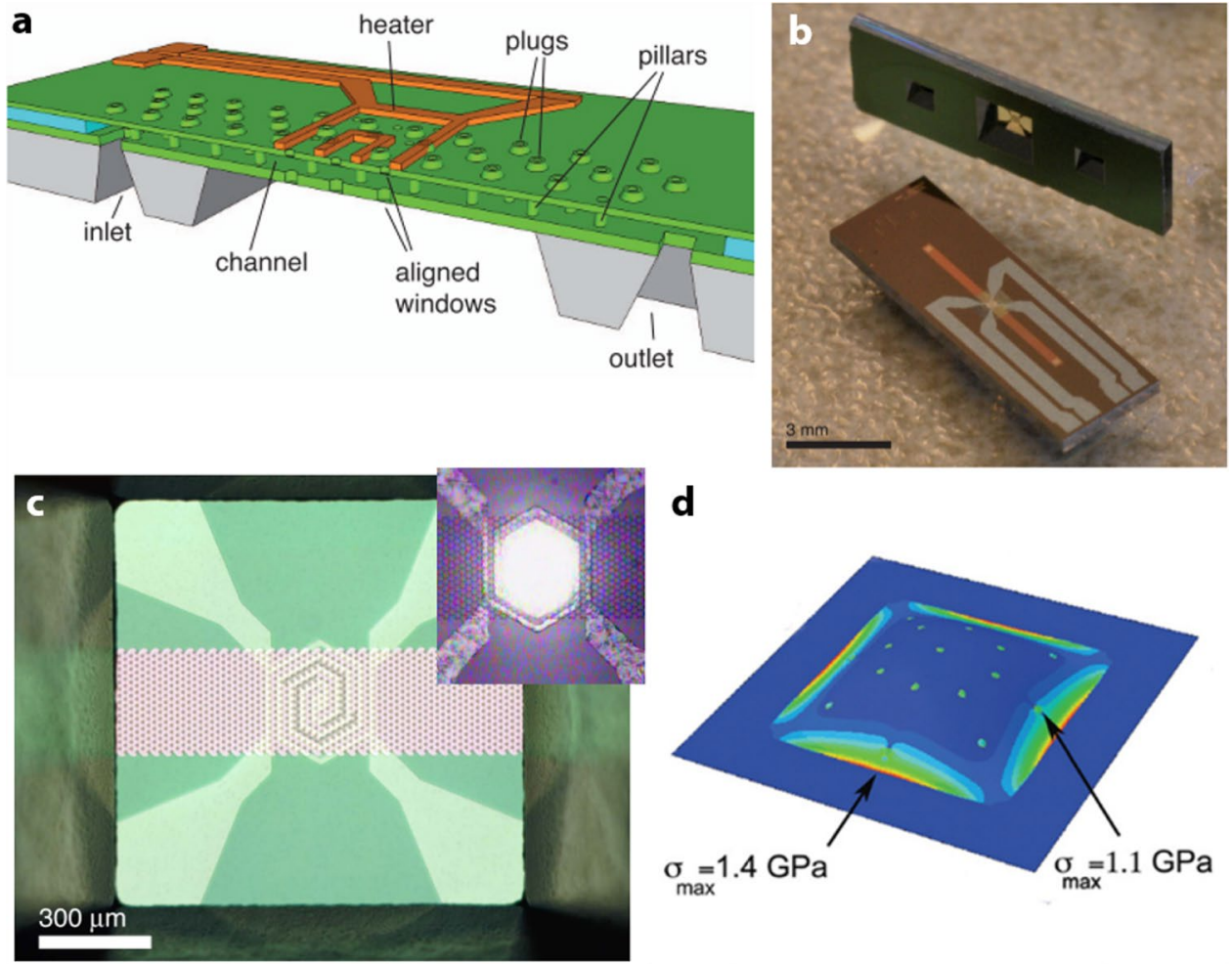

d

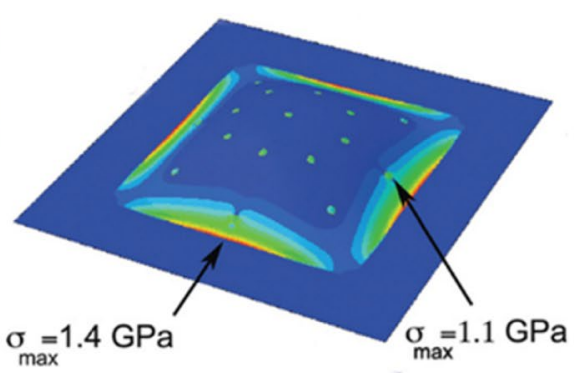




\section{Gas Cells for Correlated X-ray Studies}

Furthermore, the application of MEMS-based gas cells for the study of active heterogeneous catalysts has been extended to other microscopy techniques, such as scanning transmission X-ray microscopy (STXM) [92]. For instance, De Smit et al. [93] have carried out in situ STXM measurements using the original gas cell design from Creemer et al. $[58,59]$ the same year it was published. Correlative in situ X-ray absorption fluorescence spectroscopy (XAFS) and STEM analysis [94] were also performed in the same commercially available nanoreactors. This is extremely promising as these techniques are complementary since they probe different length scales. Another study combined STEM, electron energy loss spectroscopy (EELS) and STXM measurements on $\mathrm{Co} / \mathrm{TiO}_{2}$ Fischer-Tropsch synthesis catalysts [95]. Thanks to the polyvalence of MEMS-based environmental cells for in situ microscopy investigations, multiple in situ approaches can be correlated, as illustrated in Fig. 5.

\section{Gas Cells-On the Relevance of In Situ Results}

MEMS-based gas cells have been used to study a number of catalytic reactions. In general, applications focus on the morphological and structural evolution of catalysts under reactive conditions that mimic gas compositions, pressure and temperatures relevant to the water gas shift [96], ethylene hydrogenation [94], $\mathrm{CO}_{2}$ reduction [97] and $\mathrm{CO}$ oxidation
[23, 24, 98-101] reactions. Nanoreactors have also been used to investigate the catalyzed growth of materials such as carbon nanostructures $[102,103]$ and the occurrence of strong metal-support interactions (SMSI) [77, 104]. Examples of in situ TEM results acquired with gas cell TEM holders are shown in Fig. 6, which illustrates the formation and removal of an SMSI induced overlayer on $\mathrm{Pt}$ and $\mathrm{Pd}$ nanoparticles deposited on $\mathrm{TiO}_{2}$ supports under different reaction conditions.

It should be noted that in all of these works, with the exception of a few operando CO oxidation studies [23, 24, $100,105,106]$, catalytic activity is assumed but has not been demonstrated, i.e. catalytic conversion has not been proven in parallel to TEM observations. These $\mathrm{CO}$ oxidation studies achieved the simultaneous acquisition of conversion rates and TEM measurements. This is done using a mass spectrometer (MS) connected to the gas outlet of the in situ TEM holder [106] that allows a direct correlation of structure and reactivity and facilitates insights into local structure-function relationships $[23,24,100,105,106]$. Conversion can also be tracked via EELS analysis of the gas composition as demonstrated by Crozier et al. [107, 108]. With these independent measurements of catalytic activity, those studies have established that the structural changes they observe are directly linked to different activity regimes [24], and not merely a result of the thermal treatment. This shows that state-of-the-art gas cell TEM holders, when combined with online product analysis, can help elucidate fundamental structural and morphological aspects relevant to catalytic processes. Independent conversion measurements are
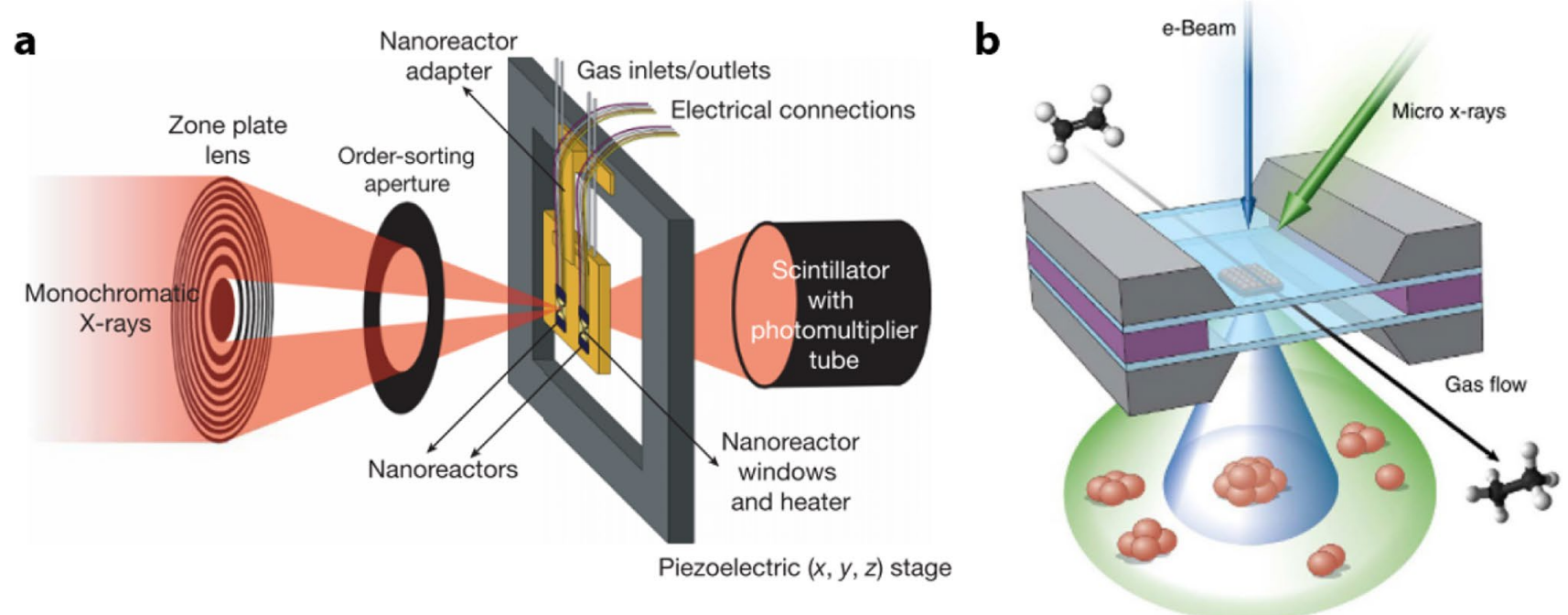

Fig. 5 In situ STXM or EXAFS and TEM analysis can be correlated using the same gas cells. a Experimental set-up adapting a commercial TEM nanoreactor for in situ STXM acquisition. b Schematic of a gas cell for correlated in situ EXAFS and STEM acquisition. In the
EXAFS experiment, all types of nanoparticles are probed, while in the STEM experiment only particles larger than $\sim 1 \mathrm{~nm}$ are detectable. Reproduced with permissions from [93] and [94] 

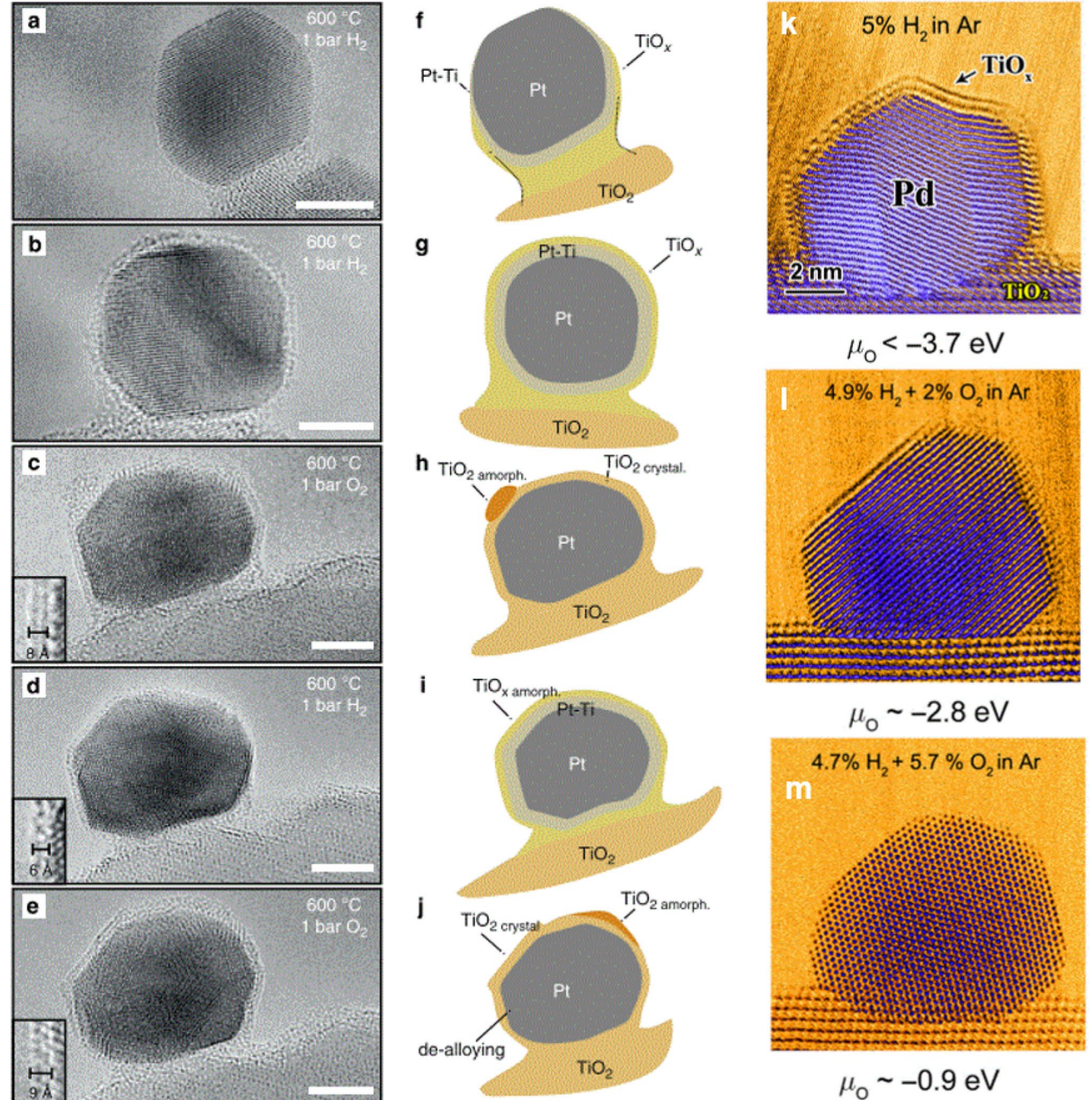

Fig. 6 Examples of applications of MEMS based gas cells for in situ TEM studies of heterogeneous catalysts. a-j Evolution and dynamic structural changes of the overlayer in SMSI of Pt NP@ $\mathrm{TiO}_{2} . \mathbf{a}, \mathbf{b}$ A Pt NP exposed to $\mathrm{H}_{2}$ at $600{ }^{\circ} \mathrm{C}$. c Subsequent change to $\mathrm{O}_{2}$. d, e Further switches between reducing and oxidizing atmosphere. $\mathbf{f}-\mathbf{j}$ Interpretation of the phenomena revealed by in situ TEM, XRD and

necessary for robust data interpretation as unsubstantiated claims could be made from in situ data alone.

Examples that highlight the importance of conversion detection can be found in some in situ TEM studies of platinum nanoparticles (Pt NPs), where it was demonstrated
XPS. Insets for $\mathbf{c}-\mathbf{e}$ show a magnified image of the observed overlayer structure. The scale bars are $5 \mathrm{~nm}$. $\mathbf{k}-\mathbf{m}$ Formation and disappearance on an overlayer on Pd NPs@ $\mathrm{TiO}_{\mathrm{x}}$ under different gas mixtures, depending on the oxygen chemical potential $\mu_{\mathrm{O}}$. Adapted from [104] and [77]

that Pt NPs undergo different surface reconstructions under oxidizing or reducing atmospheres $[99,101]$. Other studies showed that the particle size distribution changes after thermal treatments, under different gas mixtures that induced either sintering or etching processes $[109,110]$. 
Although it is claimed in these works that those evolutions result from catalytic reactions, they can only be attributed to thermal treatments in a controlled atmosphere in the absence of conversion measurements. Another study proposed to reverse the loss of activity caused by sintering at high temperature using nitrogen-doped carbon shells on Pd, Au and Pt NPs [111]. However, the morphological investigation was conducted in an Ar atmosphere rather than under realistic reaction conditions. Changing operating conditions such as the gas composition, the partial pressures, the sample composition itself, or the electron dose used can have an impact on the appearance of nanoparticles. Claims made from data acquired under conditions that differ from realistic ones will thus be controversial.

Conversion detection during in situ TEM experiments is of paramount importance, especially given the vastly different kinetics that exist between MEMS-based gas cells and fixed bed reactors (FBRs) used in real application. Once again, catalytic activity in gas cells cannot be assumed. Comparing the catalytic activity measured in both operando TEM and FBR setups may allow one to judge on whether or not in situ TEM data can safely be attributed to a certain activity regime. A detailed description of the differences between FBR and MEMS-based gas cells is presented in the following:

(i) Inlet gas flow Although the inlet gas flow of gas cell TEM holders can be adjusted from $5 \mathrm{~mL} / \mathrm{min}$ to 1 $\mu \mathrm{L} / \mathrm{min}$ [106], the gas flow is extremely fast relative to flows in FBRs due to the small volume of the nanoreactor. As a result the residence time of the gas mixture in the nanoreactor is in the millisecond regime [106], which is three orders of magnitude lower than typical values of FBRs. This is indicative of significantly different mass transport conditions. There is much more convection in MEMS based gas cells compared to FBRs.

(ii) Catalyst bed geometry MEMS-based gas cells use a flat bed of catalyst particles that are loaded directly on the $\mathrm{SiN}_{\mathrm{x}}$ window. The coverage is sparse, as particle have to be clearly separated for TEM observation. The total amount of catalyst does not exceed $1 \mu \mathrm{g}$ [106] and gases mostly diffuse over the catalyst bed rather than through it. Studies of other MEMS-based microreactors that feature similar beds of catalyst particles along the reactor walls found that catalytic processes were dominated by mass diffusion, owing to the inability of the reactant stream to adequately wet the catalyst bed [34]. In FBRs reactants migrate with lower speeds through a cylindrical, densely packed bed of supported catalysts. This makes comparing the kinetics of both systems difficult. (iii) Heat transfer Given that the particle coverage is sparse, there is no conductive heat transfer from one particle to another. Conduction is essential for faster kinetics in FBRs, as the heat of exothermic reactions can quickly thermalize the entire catalyst bed and, thus, maintain its operating temperature. Similar operation in gas cells would require the preheating of gases before flowing them in. This cannot be achieved in current commercially available gas cell TEM holders. In these nanoreactors cold gases flow fast over the deposited catalyst particles and cool them through convection. It then comes as no surprise that in operando $\mathrm{CO}$ oxidation studies [23, 24] the onset temperatures for conversion have been found to be higher than expected. Vendelbo et al. [91] used EELS measurements to show that the stagnant gas in their gas cell was on average $26^{\circ} \mathrm{C}$ colder than the temperature indicated by the microheater. Moreover, with a high gas flow through the nanoreactor there is a temperature gradient along the gas channel [59]. A review of methods for temperature calibration in in situ experiments was recently published by Gaulandris et al. [112]. Such temperature gradients could cause the reaction of interest to proceed with uneven kinetics across the catalyst bed [113]. Since MS data is averaged over the whole bed, this could then lead to biased conclusions. Variations in local kinetics have been already revealed at the microscale by photoelectron electron microscopy (PEEM) [114, 115]. We would like to emphasize that new methods are required to reproduce this work at the nanoscale.

Overall, operando experiments are uniquely suited to investigate the structural and morphological evolution of model catalytic systems (such as phase changes and surface reconstruction) and their correlation to certain activity regimes. Fundamental processes such as sintering, nucleation and growth are further examples of phenomena that can be accessed with such experiments. However, reaching robust quantitative conclusions from operando work is challenging. It requires extreme care in assessing the discrepancies between model and real systems, as kinetics in gas cells differ from that of industrial reactors.

\section{Liquid Cells}

MEMS-based nanoreactors for liquid phase reactions were developed alongside closed gas cell technology [116-118]. The advent of liquid phase nanoreactors has provided a platform to study working electrocatalysts inside the TEM column and answer questions on the local structure and morphology of materials relevant to energy conversion [9, 

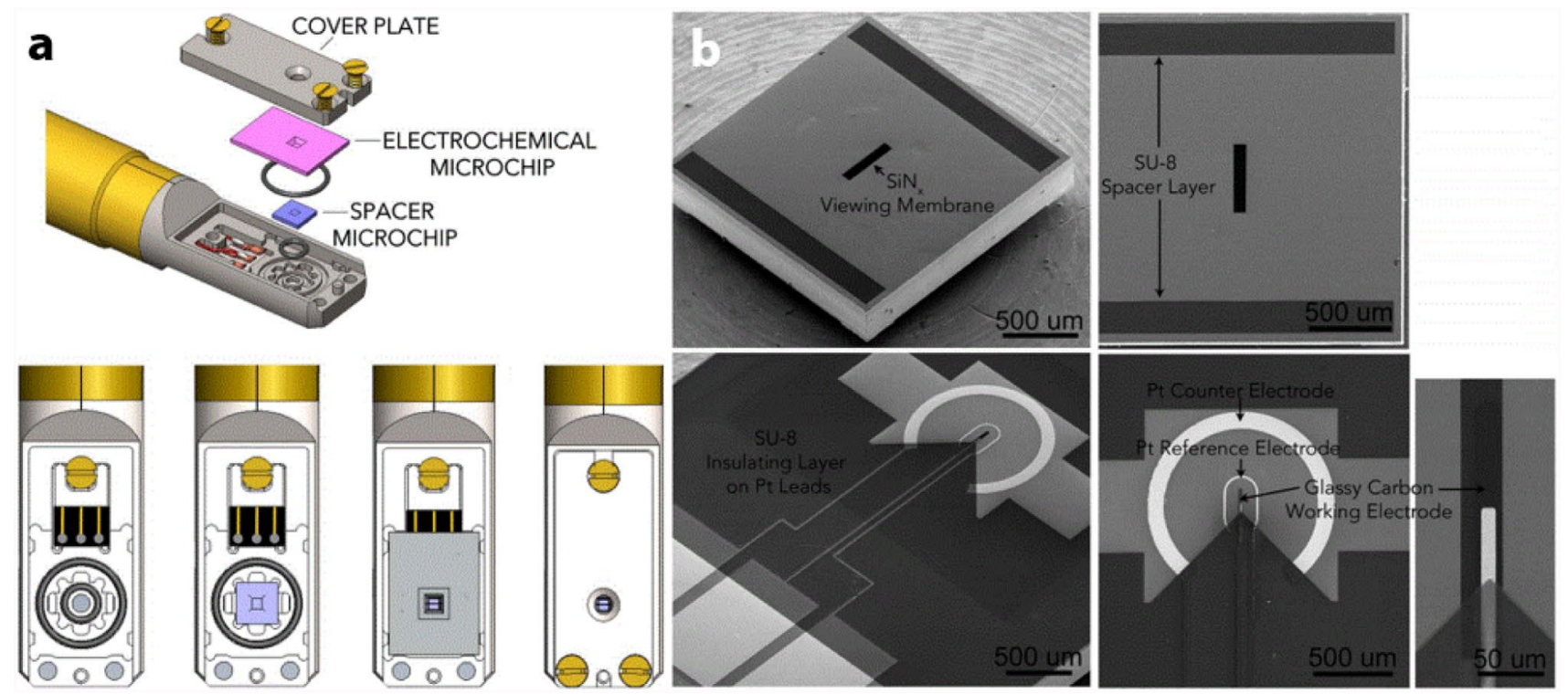

TEM holder. b SEM images of the MEMS chips used in the liquid

Fig. 7 Design of a modern MEMS based in situ TEM liquid cell. a Schematic illustration of the Protochips Poseidon 500 liquid cell system depicting the assembly of the MEMS within the tip of the in situ cell. Reproduced with permissions from [29]

indium spacer and allows for nanometer image resolution inside the TEM [121]. A microfluidic flow system [126-128] was then proposed, similar to the one described for MEMSbased TEM gas cells. This allows for the introduction and removal of solutions during experiments and facilitates cell assembly, as the cell can now be filled in situ. In addition, a SU-8 resist spacer was introduced. It is still present in today's state-of-the-art systems. With this modern cell, the authors demonstrated the possibility to track Au NPs in biological cells in a $10 \mu \mathrm{m}$ thick liquid chamber with $4 \mathrm{~nm}$ resolution by HAADF-STEM imaging [126]. It further shows that the high $\mathrm{Z}$ contrast of the HAADF detector can be used to image across thick layers of low- $Z$ materials such as water. It is worth noting that the pressure difference of one atmosphere between the inside of the liquid cell and the vacuum of the TEM column leads to significant bulging of the $\operatorname{SiN}_{\mathrm{x}}$ windows [129]. Thus the cell can be 2 to $3 \mu \mathrm{m}$ thicker in its center.

The operando capabilities of liquid phase TEM cells were further improved by patterning the MEMS chips. Up to ten Pt microelectrodes which can measure and apply currents down to the $\mathrm{pA}$ regime were integrated $[130,131]$. This enables the detection of the electrochemical response of single nano-objects. Multiple stimuli can be applied within the same experiments with these electrodes, including heating, biasing and galvanostatic control. Today, Protochips, DENS solutions and Hummingbird offer commercial liquid cell TEM holders and MEMS chips for quantitative operando electrochemistry with pA sensitivity. A schematic illustration of a modern in situ TEM liquid Protochips holder and 
SEM micrographs of the corresponding MEMS chips can be found in Fig. 7. These TEM holders have made liquid phase (S)TEM experiments an accessible characterization tool for functional materials. However, liquid cells are more difficult to assemble than their gas counterparts as they use spacers that are an order of magnitude thinner.

These thin liquid layers are necessary to minimize the background scattering for (S)TEM imaging and to reach higher SNR and resolutions. The state-of-the-art image resolution in aqueous medium is in the range of a few nanometers. Lattice resolution imaging has also been demonstrated for the in situ growth of Pt NPs [132] in a $400 \mathrm{~nm}$ thick cell with $50 \mathrm{~nm}$ thick $\mathrm{SiN}_{\mathrm{x}}$ windows. High resolution imaging was reported as well on the same system for a $100 \mathrm{~nm}$ thick cell with $10 \mathrm{~nm}$ thick windows [30]. A monolithic cell design similar to that of MEMS-based gas cells has been also proposed. It features shallow wells of fixed dimensions which can sustain liquid pressures above one atmosphere [133]. The authors demonstrated $0.24 \mathrm{~nm}$ image resolution and showed the ability to measure the O-K edge of iron oxide NPs in an aqueous medium. However, such thin cells are unlikely to be replicated for operando electrochemical investigations, as confining electrolytes introduce significant ohmic drops [134] that have a considerable impact on electrochemical measurements. Quantitative operando electrochemical measurements in liquid-phase TEM cells require cells that are micrometers thick. Commercial solutions opt for a compromise between sufficient SNR of the TEM images and the relevance of the electrochemical measurements. The technique nevertheless provides a unique opportunity to study the morphological dynamics of electrocatalytic processes down to the nanometer scale. Examples of successful applications are listed in the next section.

\section{Liquid Cells-Applications}

Liquid cell TEM experiments have been applied to study a range of different catalytic systems, including fuel cells [9]. These in situ investigations complement the quasi in situ workflows described earlier, which have also been proposed for liquid-phase studies [135, 136]. Liquid cell electrochemistry has been used for instance for the in situ study of the oxygen reduction reaction (ORR) using Pt-Fe [120], Pt-Pd [137] and Pt-Ni alloy NPs [138]. These studies have demonstrated a potential stability window, the possibility to quantify dissolution rates as a function of time and applied potential, and have shed insight on the corrosion mechanisms of carbon supports. Such insight is hardly accessible via ex situ methods, as it can only be gathered in real time.

The oxygen evolution reaction (OER) was also investigated using operando electrochemistry in MEMS-based liquid cells [139]. Ortiz Peña et al. [140] directly observed the gradual amorphization of $\mathrm{Co}_{3} \mathrm{O}_{4}$ NPs during water oxidation, showing that $\mathrm{a}-\mathrm{Co}_{3} \mathrm{O}_{4}$ is the active phase for the electrocatalytic OER over cobalt oxide catalysts. The growth of catalytic nanomaterials has also garnered significant attention. Most studies take advantage of the strong electron beam-electrolyte interactions, which are used to reduce the metallic cations inside the precursor solution and triggers precipitation [30, 31, 141, 142]. This is illustrated in Fig. 8. In these works, the dose rate controls the concentration of the reducing agents and thus the rate of reduction. As a result it determines the rate of mass transfer towards the growing crystals, allowing fine tuning of the growth conditions [143]. Using this approach, Li et al. [132] uncovered a distinct growth mechanism for iron hydroxide NPs. The authors describe a mechanism where particle pairs continuously rotate until a perfect lattice match is obtained, which initiates the atom-by-atom addition.

Electron spectroscopy techniques have been also used to study catalysts in liquid cells. Although core-loss EELS measurements remain challenging within micrometer-thick liquid layers, low-loss EELS [134, 144] and electron dispersive X-ray spectroscopy (EDS) [145] have seen promising proofs of concept. The former is effective in probing changes of the electronic structure of catalysts and important to calculate effective thicknesses through the $t / \lambda$ method [129, $133,146]$. EDS on the other hand allows for the simultaneous mapping of multiple elements at the nanoscale in liquids.

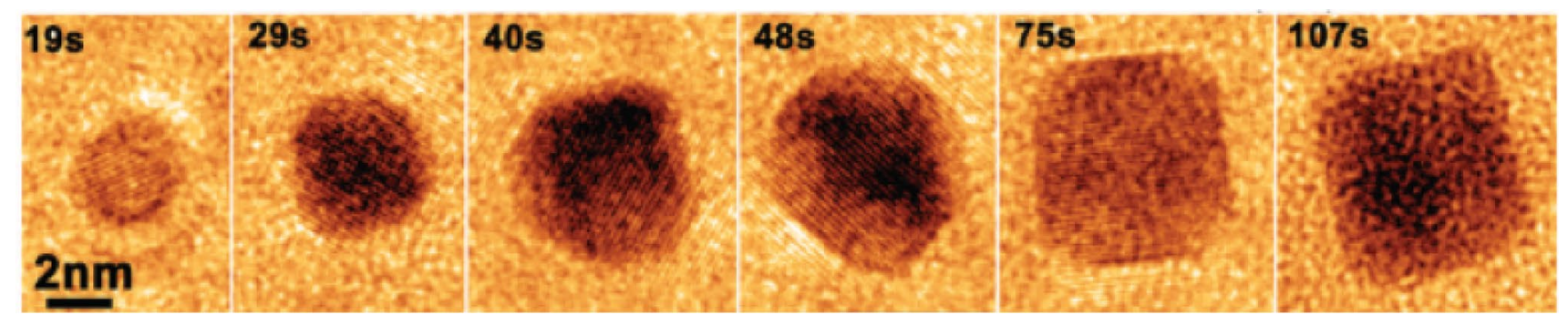

Fig. 8 Application of MEMS based in situ TEM liquid phase cells on heterogeneous catalysts. In situ facets evolution of a growing $\mathrm{Pt}$ nanocube triggered by the interaction of the electron beam with the precursor solution (viewed along the [100] axis). Reproduced with permissions from [30] 
Resolutions as low as $10 \mathrm{~nm}$ have been demonstrated [145]. Images with higher resolution are achievable and have been demonstrated in extremely thin cells that consist of liquids that are confined within 2D materials, such as graphene or boron nitride heterostructures [147, 148]. Those are, however, outside the scope of the present review.

\section{Liquid Cells-Challenges}

Although state-of-the-art setups come with the promise of quantitative electrochemical measurements and nanometer resolution, the reality is more nuanced. Both TEM and electrochemistry measurements are still mostly limited by the interaction of the electron beam with the liquid medium. Irradiation induces radiolysis in the electrolyte, which produces molecular and radical products such as atomic hydrogen and oxygen species, as well as solvated electrons [123, 149]. The steady-state concentration of radiolysis products was calculated by Schneider et al. (Fig. 9b). From this we can estimate the concentration of radiolysis products that were present in the experiment conducted by Liao et al. which is illustrated in Fig. 8. Their reported beam density is $5 \times 10^{5} \mathrm{~A} / \mathrm{m}^{2}$ or about $1.2 \times 10^{11} \mathrm{~Gy} / \mathrm{s}$ (according to the approximation from De Jonge et al. [118]) and gives $\left[\mathrm{H}^{\cdot}\right] \approx 10^{-5} \mathrm{M}$ and $\left[\mathrm{OH}^{\cdot}\right] \approx 10^{-3} \mathrm{M}$. Such high concentrations of radicals are significant to the reactions of interest and they cannot be neglected. In some cases, in particular when hydrocarbon species are involved, radicals can be stabilized by inductive effects or the formation of resonance structures [150]. This increases the lifetime of the radicals, which are then more likely to react with the electrolyte or the catalyst surface. It will also affect ongoing electrochemical measurements such as cyclic voltammetry and can complicate the interpretation of the results. Unocic et al. [29] show for example that current profiles are offset by a few nA, if the electron beam is either on or off. This is significant given that the electrochemical response of individual nano-objects that are imaged can be in the order of $\mathrm{pA}$, but could be dismissed when looking at larger systems.

Furthermore, Schneider et al. [123] showed that the steady state concentrations of radiolysis products varies greatly depending on the initial $\mathrm{pH}$ value of the electrolyte. These products will in turn modify the $\mathrm{pH}$ value and trigger, for instance, otherwise stable colloidal suspensions to aggregate under the beam [124, 143, 151]. Redox potentials also strongly depend on the $\mathrm{pH}$ and may be locally affected through this mechanism. This could induce different chemical dynamics in individual irradiated NPs. Moreover, NPs have been observed to either get etched or to grow under the electron beam. The extent of this phenomenon depends on the relative proportion of oxidizing or reducing radiolysis products [123].

It has been proposed that beam effects can be dismissed entirely if an appropriately low dose, inferior to the electrolyte damage threshold, is used [134, 144]. However, it is worth noting that this dose threshold is an order of magnitude higher for the carbonate solvent used in this study than for water. It is challenging in liquid-phase TEM experiments to keep the electron dose rate below the threshold value for complete water decomposition, which produces $\mathrm{H}_{2}$ bubbles [152] and is detrimental to TEM imaging and mass transport in the cell. In a recent in situ study focusing on photocatalytic water splitting over $\mathrm{TiO}_{2}$ [153], a direct causal link is proposed between the observation of $\mathrm{H}_{2}$ bubbles and the catalytic activity. This conclusion was only possible after beam effects were dismissed thanks to rigorous control experiments. If bubble formation cannot be avoided, a flow cell can be beneficial since it accelerates the removal of irradiation products compared to a stagnant cell. It is worth noting here that additional mass and heat transfer is to be expected in flow cells, thus helping mitigate the formation of gradients

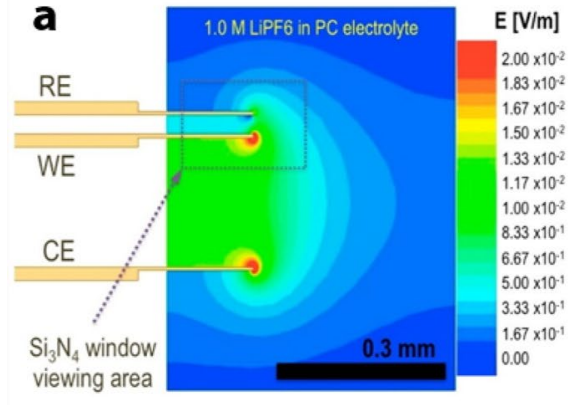

Fig. 9 Illustrations of phenomena to consider for in situ TEM liquid cells studies and examples of applications on heterogeneous catalysts. a ANSYS Maxwell static 3D electromagnetic finite element simulation of the electric field distribution in the in situ ec-liquid. b Cal-

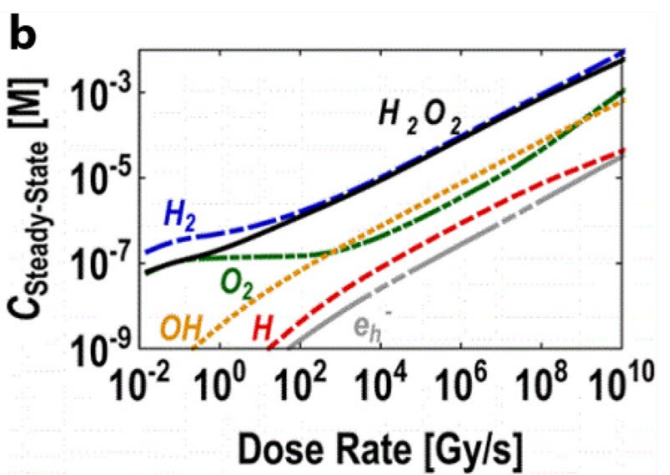

culated concentration of radiolysis products as a function of electron dose rate as a result of electron beam interactions with the aqueous medium. Reproduced with permissions from [123, 134] 
that might appear under irradiation. In addition, the flow could affect the motion of NPs in tracking experiments. The factors affecting the apparent diffusion of NPs in in situ TEM experiments were analyzed by Yesibolati et al. [129].

Lastly, the geometry of electrodes has to be considered as well in operando electrochemical measurements. Both the concentric [120,154] and linear [134] electrode geometries available in commercial MEMS based systems do not create homogeneous electric fields, as illustrated in Fig. 9a. During the electrochemical reduction of metal cations, the nucleation or growth rates of NPs could be locally higher at the local maxima of the electric fields, or "hot spots". This, alongside irradiation effects, should be carefully considered if reliable assessments of reaction products are to be made. Low-dose methodologies $[153,155,156]$ can be used to reduce beam effects to a minimum.

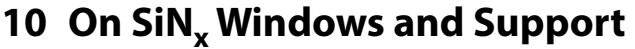 Interactions}

Although several methodology and instrumentation papers have been published on in situ MEMS-based cells [106, 157], only a few have specifically discussed the role of $\mathrm{SiN}_{\mathrm{x}}$ windows, which are the cornerstones of MEMS-based nanoreactors. In this section, we discuss why $\mathrm{SiN}_{\mathrm{x}}$ materials are best for this application, their corrosion under particular operating conditions, and their role as catalyst supports when catalyst particles are directly deposited on $\operatorname{SiN}_{x}$ windows.

$\mathrm{SiN}_{\mathrm{x}}$ materials deposited by low-pressure chemical vapor deposition (LPCVD) meet a number of criteria for gas cell TEM windows: (i) their amorphous structure does not contribute any diffraction background to TEM observations. It is worth mentioning that in our own work $\mathrm{SiN}_{\mathrm{x}}$ has been observed to crystallize in situ when temperatures above $800{ }^{\circ} \mathrm{C}$ are used under an oxygen-containing atmosphere. (ii) Silicon nitrides are chemically relatively inert, heat resistant and heat conductive [58, 158]. It should be noted that $\mathrm{SiN}_{\mathrm{x}}$ windows can in fact corrode under specific conditions $[159,160]$, which has to be taken into account for the planning of in situ experiments. Corrosion studies revealed that $\mathrm{SiN}_{\mathrm{x}}$ oxidation is aided by water vapor in an oxygen atmosphere [160]. In addition, our work has shown the corrosion and breakage of the $\mathrm{SiN}_{\mathrm{x}}$ window under $\mathrm{O}_{2}$ and $\mathrm{H}_{2}$ mixture at high temperature. (iii) The mechanical strength of $\mathrm{SiN}_{\mathrm{x}}$ allows the thin windows to sustain the colossal pressure difference that exists between the closed cell operating at atmospheric pressure and the high vacuum of the TEM column, even at thicknesses compatible with electron transparency. There are few other material candidates that have been tested for the design of closed cells. Attempts at using alumina windows were of limited use [60]. Amorphous carbon can be readily attacked by chemicals and does not possess sufficient mechanical strength. Graphene on the other hand contributes extremely little scattering background to TEM measurements, but graphene cells are exceedingly difficult to produce reproducibly, are of random dimensions, and do not allow for the application of external stimuli [161]. However, advanced 2-dimensional (2-D) heterostructures that stack patterned flakes of boron nitride and graphene have been proposed to build cells of total thicknesses of $30 \mathrm{~nm}$ or thinner in a reliable manner [148]. These 2-D cells could be used for liquid phase studies that use the electron beam as the sole external stimulus, but not for experiments that require heating or flowing of gases and liquids. Recently, the in situ capability of such 2-D heterostructures has been demonstrated for the lithiation of a graphene sheet [162], where a bias was applied to a graphene cell. In the future, such highly specialized devices might be tailored from 2D materials to fit the requirements of specific experiments.

$\mathrm{SiN}_{\mathrm{x}}$ windows often act as catalyst supports, as catalyst particles can be directly prepared on their surface [23, 24, 105]. The catalytic properties of deposited materials are affected through support interactions [158]. Thus, an inhomogeneous $\mathrm{SiN}_{\mathrm{x}}$ surface could play a role in the uneven behavior of NPs under reaction conditions as seen for instance, in operando investigations of the morphological evolution of Pt NPs [24]. Although further studies are required, it can be hypothesized that some particles show lesser activity because of different local metal-support interactions mediated by local inhomogeneities in the $\mathrm{SiN}_{\mathrm{x}}$ window surface. Studies of $\mathrm{SiN}_{\mathrm{x}}$ as a catalyst support have shown that amorphous $\mathrm{SiN}_{\mathrm{x}}$ supports are detrimental to the catalytic performance of $\mathrm{Pt}$ catalysts for the partial oxidation of methane, as it forms a $\mathrm{SiO}_{2}$ overlayer on the Pt NPs [163]. Moreover, $\mathrm{Pt} / \mathrm{a}-\mathrm{SiN}_{\mathrm{x}}$ catalysts have shown catalytic activity superior to $\mathrm{Pt} / \mathrm{MgO}$ reference systems for propane dehydrogenation which was attributed to the basic nature of $\mathrm{SiN}_{\mathrm{x}}[158]$. Hullman et al. [164] showed that carbon, boron or titanium doping of the $\mathrm{SiN}_{\mathrm{x}}$ support can significantly influence its catalytic properties. Similar support effects could be present when other metals are used as dopants.

In the course of the development of MEMS-based cells manufacturers and researchers have also tuned the composition of $\mathrm{SiN}_{\mathrm{x}}$ to optimize the internal tensile stress of the windows [165]. This minimizes bulging and allows for higher pressures in the nanoreactors. It has been shown that higher silicon contents are desirable for this application [166], i.e. compositions closer to $\mathrm{SiN}$ are preferred compared to the stoichiometric $\mathrm{Si}_{3} \mathrm{~N}_{4}$. Silicon atoms can be more easily oxidized in such silicon-rich compositions and a case can be made for a likely oxygen or $\mathrm{OH}$ termination on the surface of the windows. Santos Aires et al. [158] performed $\mathrm{X}$-ray photoelectron spectroscopy (XPS) measurements on amorphous $\mathrm{SiN}_{\mathrm{x}}$ particles and found significant amounts of 
surface oxygen. Zaluzec et al. detected small amounts of both $\mathrm{O}$ and $\mathrm{Cl}$ incorporated into $\mathrm{SiN}_{\mathrm{x}}$ films deposited by LPCVD [167]. Control EELS measurements in an operando TEM study have also revealed oxygen in $\mathrm{SiN}_{\mathrm{x}}$ membranes [133]. Other works reported the presence of a duplex oxide layer on CVD $\mathrm{SiN}_{\mathrm{x}}$. The layer was found to consist of an outer layer of silica and an inner layer of silicon oxynitride [168].

It is our opinion that working with catalyst supports whose metal-support interactions are better understood compared to the support effects of $\mathrm{SiN}_{\mathrm{x}}$ windows leads to more robust interpretations of the results and should be preferred. This can be accomplished by modifying chips through the same microfabrication techniques that are involved in the fabrication of MEMS devices. These techniques include optical and e-beam lithography to pattern chips with thin film depositions from CVD techniques, such as atomic layer deposition (ALD). Focused ion beam (FIB) patterning is another possibility. Using such processes, MEMS chips have already been modified with oxide layers such as $\mathrm{Al}_{2} \mathrm{O}_{3}[169]$ that acted as catalyst support in subsequent in situ studies.

\section{On Cell Thickness}

Another crucial parameter for in situ TEM experiments using MEMS based gas cells is the overall thickness of the closed cell. Since the density of gases is almost three orders of magnitude lower than it is for liquids, the overall thickness of the cell matters most during liquid-phase experiments. The thickness of the cell can be adapted quickly to specific experimental needs by varying the thickness of SU-8 spacers. It is worth noting here that the presence of such organic materials in the cell has the drawback of making carbon contamination a major problem at low operating temperatures in gas cells. Below $200{ }^{\circ} \mathrm{C}$, thick carbon layers are deposited under the beam and make (S)TEM observation impossible.

In liquid cells, the electrolyte layer significantly contributes to the additional scattering background measured in TEM images. Thinner cells are thus desirable, as they contribute a lower background and lead to a better SNR, which can result in high resolution images as demonstrated by Liao et al. with a liquid layer as thin as $100 \mathrm{~nm}$ [30] and $10-\mathrm{nm}$ thick windows. Thinner windows $(<30 \mathrm{~nm})$ are worthwhile for thin cells, as they significantly reduce the total scattering from the cell. Although additional bulging is to be expected compared to thicker windows it can be considered a good trade-off. In thick cells however, the windows account for a smaller proportion of the total scattering. Thus, thinner windows will not significantly improve the SNR. In addition, bulging will increase liquid thickness and will thus enhance the total scattering, which will outweigh the benefits of thinner windows in thick cells. Bulging has been reported to cause cells with 10-nm thick windows to increase from 2 to $35 \mu \mathrm{m}$ [59] inside the TEM. Thinner windows are also significantly more prone to fracture than their thicker counterparts and it is more difficult to fabricate them reliably. They are therefore currently not offered by commercial manufacturers. For gas cells, it is debatable whether such thin windows are necessary to HR(S)TEM operation in the first place, as atomic resolution has also been demonstrated through $30 \mathrm{~nm}$ windows [77]. For liquid cells, there are theoretical arguments for an ultimate limit in the resolution achievable in aqueous medium. It was calculated that Angström resolution requires electron beam doses that are above the radiolysis threshold of water and as such quantitative high resolution TEM is not readily accessible in aqueous environments with currently available instruments [118].

The SNR depend on the effective cell thickness including bulging effects and on the gas density. A thorough discussion of the parameters affecting TEM resolution in gas cells is provided by Xin et al. [170]. For liquid cells, the dependence of the achievable resolutions and of the contrast on the electron dose, the dose rate and the cell thickness has been recently reviewed by De Jonge et al. [118]. Another phenomenon relevant to in situ TEM measurements is the so-called top-bottom effect [170]. In TEM, the object of interest is preferably located at the exit (bottom) surface. This reduces the elastic blurring of the object's exit wave. Since elastic scattering scales with the square root of the thickness $\left(\mathrm{t}^{1 / 2}\right)$, resolution deteriorates noticeably as the gas path lengths reaches $1 \mu \mathrm{m}[170]$. However, for objects that are on the bottom membrane, the effect only becomes significant when the gas path length approaches $40 \mu \mathrm{m}$. For this reason, Protochips [171] for instance sells top and bottom chips of different window thicknesses, in either TEM or STEM configurations. In TEM mode specimens should be loaded on the bottom chip, which features in that case a thinner window. Conversely STEM operation benefits from specimen being loaded on the top chip, again with a thinner window, to avoid beam broadening.

\section{Conclusion and Perspectives for MEMS Based TEM Cells}

In this review, we have put forward a discussion on the complexity of performing operando and in situ experiments with MEMS based nanoreactors applied to study heterogeneous catalysts. Gas and liquid-phase in situ TEM nanoreactors have emerged over the last decade, combining MEMS catalytic microreactor technology with early closed in situ cell approaches for the TEM and advances in MEMS microheaters. The commercialization of standardized in situ TEM cells and holders has now made the study of catalysts at 
atmospheric pressure readily accessible for electron microscopy laboratories around the world.

However, there remains great challenges in interpreting in situ catalysis work conducted inside the TEM. Structural and morphological evolutions cannot be readily linked to catalytically relevant events unless activity can be followed operando with mass spectrometry readings. This is necessary for the study of catalytic reactions. Few groups have published such operando TEM work so far. In our opinion there are three possibilities to determine catalytic conversion from MEMS based systems: EELS analysis [107, 172], online MS measurements [106] or prospectively the deposition of chemical sensors next to the active species. These chemical sensors can react with the products and the changes in the sensors related to electronic or geometric structure can be detected. Correlating conversion measurements is especially important given the vast differences that exists between industrially relevant FBRs and the in situ cells, which lead to very different kinetics. Generally, independent measurements of the operating conditions are needed for robust data interpretation, as chemical dynamics are strongly dependent on all reaction parameters. It could also be useful to calculate and report the chemical potentials used in in situ works, so that experiments can be compared on that basis. This is important since it is extremely challenging to replicate the operating conditions of another setup.

For example, studies have shown that significant temperature gradients inside a gas cell can exists and that operating temperature differs from the nominal one [91]. Similarly, the operating pressure could be checked operando to assess whether there are unaccounted pressure drops. Piezoelectric MEMS pressure sensors [173] could be integrated into existing in situ TEM systems for that purpose. $\mathrm{pH}$ sensors could be built in liquid cell chips for reference experiments as well, although such technology is not yet readily available to our knowledge [174]. For reactions such as ammonia synthesis that operate at pressures above 50 bars, a pressure gap remains for in situ work. Although alternative high pressure gas cell designs have been proposed, they have to our knowledge not been used in complete catalysis studies and have stayed proofs of concept. It is also unclear whether TEM observations of satisfactory SNR could be acquired with the higher background that would come with higher pressures. Thus quasi in situ workflows remain the method of choice reactions operating at such high pressures.

In liquid cells, electron beam-electrolyte interactions are paramount to in situ TEM studies and need to be carefully taken into account. Radiolysis products affect both TEM observations (bubble formation) and electrochemical measurements, and modify the $\mathrm{pH}$ value in aqueous medium. It can thus be difficult to discern the phenomena of interest from beam-induced phenomena, and rigorous control experiments are needed. Irradiation can accelerate sintering, reconstruction, or other chemical reactions in nanocatalyst systems, both in the gas and liquid phases. The chemistry of radical species produced by radiolysis with the environment should be carefully considered. The case of oxygen species may serve as an example. Each oxygen molecule can react stepwise with four electrons and form three different radical compounds that correspond to different redox potentials, which are presented Table 1 . Such species can be chemically reductive $\left(\mathrm{O}_{2}^{-\cdot}\right)$ or oxidative. This Janus-type behavior of the reactivity of activated oxygen molecules makes beaminduced chemistry a complex matter, and data interpretation of in situ data even more so.

Furthermore, TEM imaging is a very local technique. It is thus desirable to correlate TEM observations with other characterization techniques for robust interpretations, as done in the joint in situ STXM and TEM experiments discussed earlier in this article. Combining in situ or quasi in situ TEM results, which generally cover a few nanoparticles, with environmental scanning electron microscopy (ESEM) for instance would allow one to correlate time-resolved measurements at different length scales. It is also desirable to conduct operando TEM analyses of catalysts at different pressures to meet the pressure limitations of all complementary techniques, such as ESEM or X-ray spectroscopy. Automated data analysis methods are also needed to translate visual observables into easy-to-read data representations for non-electron microscopy experts and foster collaborations.

Ideally, in situ TEM experiments would enable researchers to observe individual conversion events at active sites. However, active sites cannot be imaged with the temporal resolution of current differentially pumped TEMs, as they are continuously produced and destroyed on the surface of heterogeneous catalysts with lifetimes in the picoseconds [176]. Observing active site is made even more difficult by the fact that they are randomly distributed over the surface of particles, owing to the fact that their creation depend on local chemical potentials. In addition, the ratio of active to inactive surface sites is low, making a potential detection of active sites extremely challenging. Moreover, it is questionable whether active sites could reliably be identified during operando TEM experiments in the first place, as that would require electron beam effects and catalytic phenomena to be completely disentangled. This would be extremely difficult

Table 1 Redox potentials of selected oxygen species derived from the liquid phase at $\mathrm{pH} 7$ [175]

\begin{tabular}{lll}
\hline Reduced species & $\begin{array}{l}\text { Oxidized spe- } \\
\text { cies }\end{array}$ & Redox potential [V] \\
\hline $\mathrm{O}_{2}^{--}$(superoxide radical) & $\mathrm{O}_{2}$ & -0.33 \\
$\mathrm{O}_{2}{ }^{2-}$ (peroxide anion) & $\mathrm{O}_{2}$ & +0.281 \\
$2 \mathrm{O}^{2-}$ (oxide anion) & $\mathrm{O}_{2}$ & +0.815 \\
\hline
\end{tabular}


given the high electron doses involved in high resolution TEM imaging, and the fact that the surface of a working catalyst is metastable, and thus prone to irradiation damage.

All in all, TEM nanoreactors have emerged to be a ubiquitous characterization tool in heterogeneous catalysis. Future operando work will greatly contribute to shed light on structure-property relationships and chemical dynamics, which are helping to take catalyst design towards knowledge-based tailoring, departing from common empirical approaches. The initial question of this article, "quo vadis MEMS?" for catalysis needs to be tackled in an interdisciplinary environment involving suppliers, material scientists, electron microscopists and catalysis researchers. Such a collaboration is necessary to develop the future of MEMS-based nanoreactors.

Acknowledgements All previous and current members of the electron microscopy group of the department of inorganic chemistry at FirtzHaber-Institut der Max-Planck-Gesellschaft are acknowledged for their excellent work on chemical, in situ and operando electron microscopy.

Author Contributions Article idea: TL. Literature research and writing: MB. Critical revisions: TL, MP, RS.

Funding Open Access funding enabled and organized by Projekt DEAL. This work was funded by the Deutsche Forschungsgemeinschaft (DFG, German Research Foundation) under Germany's Excellence Strategy - EXC 2089/1-390776260.

\section{Compliance with Ethical Standards}

Conflict of interest All the authors declared that they have no conflict of interest.

Open Access This article is licensed under a Creative Commons Attribution 4.0 International License, which permits use, sharing, adaptation, distribution and reproduction in any medium or format, as long as you give appropriate credit to the original author(s) and the source, provide a link to the Creative Commons licence, and indicate if changes were made. The images or other third party material in this article are included in the article's Creative Commons licence, unless indicated otherwise in a credit line to the material. If material is not included in the article's Creative Commons licence and your intended use is not permitted by statutory regulation or exceeds the permitted use, you will need to obtain permission directly from the copyright holder. To view a copy of this licence, visit http://creativecommons.org/licenses/by/4.0/.

\section{References}

1. Pennycook SJ, Boatner LA (1988) Chemically sensitive structure-imaging with a scanning transmission electron microscope. Nature 336:565-567. https://doi.org/10.1038/336565a0

2. Haider M, Uhlemann S, Schwan E et al (1998) Electron microscopy image enhanced. Nature 392:768-769. https://doi. org/10.1038/33823
3. Batson PE, Dellby N, Krivanek OL (2002) Sub-aångstrom resolution using aberration corrected electron optics. Nature 418:617-620. https://doi.org/10.1038/nature00972

4. Urban KW (2008) Studying atomic structures by aberration-corrected transmission electron microscopy. Science 80-(321):506510. https://doi.org/10.1126/science. 1152800

5. Crozier PA, Hansen TW (2015) In situ and operando transmission electron microscopy of catalytic materials. MRS Bull 40:38-45. https://doi.org/10.1557/mrs.2014.304

6. Taheri ML, Stach EA, Arslan I et al (2016) Current status and future directions for in situ transmission electron microscopy. Ultramicroscopy 170:86-95. https://doi.org/10.1016/j.ultra mic.2016.08.007

7. Tao F, Salmeron M (2011) In situ studies of chemistry and structure of materials in reactive environments. Science 80-(331):171-174. https://doi.org/10.1126/science.1197461

8. Dai S, Gao W, Graham GW, Pan X (2018) In situ atmospheric transmission electron microscopy of catalytic nanomaterials. MRS Adv 3:2297-2303. https://doi.org/10.1557/adv.2018.435

9. Hwang S, Chen X, Zhou G, Su D (2020) In situ transmission electron microscopy on energy-related catalysis. Adv Energy Mater 10:1902105. https://doi.org/10.1002/aenm.201902105

10. He B, Zhang Y, Liu X, Chen L (2020) In-situ transmission electron microscope techniques for heterogeneous catalysis. ChemCatChem 12:1853-1872. https://doi.org/10.1002/cctc.201902285

11. Wu J, Shan H, Chen W et al (2016) In situ environmental TEM in imaging gas and liquid phase chemical reactions for materials research. Adv Mater 28:9686-9712. https://doi.org/10.1002/ adma.201602519

12. Wu F, Yao N (2015a) Advances in windowed gas cells for in-situ TEM studies. Nano Energy 13:735-756. https://doi. org/10.1016/j.nanoen.2015.03.015

13. Ye F, Xu M, Dai S et al (2020) In situ tem studies of catalysts using windowed gas cells. Catalysts 10:1-20. https://doi. org/10.3390/catal10070779

14. Tao F, Crozier PA (2016) Atomic-scale observations of catalyst structures under reaction conditions and during catalysis. Chem Rev 116:3487-3539. https://doi.org/10.1021/cr5002657

15. Seymour JP, Wu F, Wise KD, Yoon E (2017) State-of-the-art mems and microsystem tools for brain research. Microsyst Nanoeng 3:1-16. https://doi.org/10.1038/micronano.2016.66

16. Arlett JL, Myers EB, Roukes ML (2011) Comparative advantages of mechanical biosensors. Nat Nanotechnol 6:203-215. https:// doi.org/10.1038/nnano.2011.44

17. Gad-el-Hak M (2001) The MEMS handbook. CRC Press, Boca Raton

18. Löwe H, Ehrfeld W (1999) State-of-the-art in microreaction technology: concepts, manufacturing and applications. Electrochim Acta 44:3679-3689. https://doi.org/10.1016/S0013 $-4686(99) 00071-7$

19. Min KB, Tanaka S, Esashi M (2006) Fabrication of novel MEMS-based polymer electrolyte fuel cell architectures with catalytic electrodes supported on porous $\mathrm{SiO} 2$. J Micromech Microeng 16:505-511. https://doi.org/10.1088/0960-1317/16/3/005

20. Kim T, Hwang JS, Kwon S (2007) A MEMS methanol reformer heated by decomposition of hydrogen peroxide. Lab Chip 7:835841. https://doi.org/10.1039/b700040e

21. Korotcenkov G, Do HS, Stetter JR (2009) Review of electrochemical hydrogen sensors. Chem Rev 109:1402-1433. https:// doi.org/10.1021/cr800339k

22. Kooyman PJ (2017) Development of operando transmission electron microscopy. In: Frenken J, Groot I (eds) Operando research in heterogeneous catalysis. Springer International Publishing, Cham, pp 111-129

23. Vendelbo SB, Elkjær CF, Falsig H et al (2014) Visualization of oscillatory behaviour of $\mathrm{Pt}$ nanoparticles catalysing $\mathrm{CO}$ 
oxidation. Nat Mater 13:884-890. https://doi.org/10.1038/nmat4 033

24. Plodinec M, Nerl HC, Girgsdies F et al (2020) Insights into chemical dynamics and their impact on the reactivity of Pt nanoparticles during CO oxidation by operando TEM. ACS Catal 10:3183-3193. https://doi.org/10.1021/acscatal.9b03692

25. Helveg S, Kisielowski CF, Jinschek JR et al (2015) Observing gas-catalyst dynamics at atomic resolution and single-atom sensitivity. Micron 68:176-185. https://doi.org/10.1016/j.micro n.2014.07.009

26. Dai S, Gao W, Zhang S et al (2017) Transmission electron microscopy with atomic resolution under atmospheric pressures. MRS Commun 7:798-812. https://doi.org/10.1557/mrc.2017.125

27. Ertl G, Knözinger H, Weitkamp J (1997) Handbook of heterogeneous catalysis. Wiley, New York

28. Hodnik N, Dehm G, Mayrhofer KJJJ (2016) Importance and challenges of electrochemical in situ liquid cell electron microscopy for energy conversion research. Acc Chem Res 49:2015-2022. https://doi.org/10.1021/acs.accounts.6b00330

29. Unocic RR, Sacci RL, Brown GM et al (2014) Quantitative electrochemical measurements using in situ ec-S/TEM devices. Microsc Microanal 20:452-461. https://doi.org/10.1017/S1431 927614000166

30. Liao H-GHG, Zherebetskyy D, Xin H et al (2014) Facet development during platinum nanocube growth. Science 80-(345):916919. https://doi.org/10.1126/science.1253149

31. Park JH, Grogan JM, Bau HH et al (2012) In situ liquid cell transmission electron microscopic observation of electron beam induced Au crystal growth in a solution. Microsc Microanal 18:1098-1099. https://doi.org/10.1017/S1431927612007349

32. Losey MW, Schmnidt MA, Jensen KF (2001) Microfabricated multiphase packed-bed reactors: characterization of mass transfer and reactions. Ind Eng Chem Res 40:2555-2562. https://doi. org/10.1021/ie000523f

33. Jensen KF (2001) Microreaction engineering — is small better? Chem Eng Sci 56:293-303. https://doi.org/10.1016/S0009 $-2509(00) 00230-\mathrm{X}$

34. Widdis SJ, Asante K, Hitt DL et al (2013) A MEMS-based catalytic microreactor for a $\mathrm{H} 2 \mathrm{O} 2$ monopropellant micropropulsion system. IEEE/ASME Trans Mechatron 18:1250-1258. https:// doi.org/10.1109/TMECH.2013.2249085

35. Saif MTA, MacDonald NC (1996) A millinewton microloading device. Sens Actuators A Phys 52:65-75. https://doi. org/10.1016/0924-4247(96)80127-0

36. Haque MA, Saif MTA (2002) In-situ tensile testing of nano-scale specimens in SEM and TEM. Exp Mech 42:123-128. https://doi. org/10.1177/0018512002042001797

37. Zhu Y, Moldovan N, Espinosa HD (2005) A microelectromechanical load sensor for in situ electron and x-ray microscopy tensile testing of nanostructures. Appl Phys Lett 86:013506. https ://doi.org/10.1063/1.1844594

38. Colla MS, Amin-Ahmadi B, Idrissi H et al (2015) Dislocationmediated relaxation in nanograined columnar palladium films revealed by on-chip time-resolved HRTEM testing. Nat Commun 6:1-8. https://doi.org/10.1038/ncomms6922

39. Sharpe WN (2008) A review of tension test methods for thin films. In: Materials Research Society Symposium Proceedings. Cambridge University Press, pp 3-14

40. Espinosa HD, Bernal RA, Filleter T (2012) In situ TEM electromechanical testing of nanowires and nanotubes. Small 8:32333252. https://doi.org/10.1002/smll.201200342

41. Peng B, Locascio M, Zapol P et al (2008) Measurements of near-ultimate strength for multiwalled carbon nanotubes and irradiation-induced crosslinking improvements. Nat Nanotechnol 3:626-631. https://doi.org/10.1038/nnano.2008.211
42. Haque MA, Espinosa HD, Lee HJ (2010) MEMS for in situ testing - Handling, actuation, loading, and displacement measurements. MRS Bull 35:375-381. https://doi.org/10.1557/mrs20 10.570

43. Nafari A, Karlen D, Rusu C et al (2008) MEMS sensor for in situ TEM atomic force microscopy. J Microelectromechanical Syst 17:328-333. https://doi.org/10.1109/JMEMS.2007.912714

44. Xu Y, MacDonald NC, Miller SA (1995) Integrated micro-scanning tunneling microscope. Appl Phys Lett 67:2305. https://doi. org/10.1063/1.115134

45. Tabak FC, Disseldorp ECM, Wortel GH et al (2010) MEMSbased fast scanning probe microscopes. Ultramicroscopy 110:599-604. https://doi.org/10.1016/j.ultramic.2010.02.018

46. Lutwyche MI, Wada Y (1995) Manufacture of micromechanical scanning tunnelling microscopes for observation of the tip apex in a transmission electron microscope. Sens Actuators A Phys 48:127-136. https://doi.org/10.1016/0924-4247(94)00986-R

47. Zhang M, Efremov MY, Schiettekatte F et al (2000) Size-dependent melting point depression of nanostructures: nanocalorimetric measurements. Phys Rev B 62:10548-10557. https://doi. org/10.1103/PhysRevB.62.10548

48. Heide HG (1962) Electron microscopic observation of specimens under controlled gas pressure. J Cell Biol 13:147-152. https:// doi.org/10.1083/jcb.13.1.147

49. Green ED, Kino GS (1991) Atmospheric scanning electron microscopy using silicon nitride thin film windows. Cit J Vac Sci Technol B 9:1557. https://doi.org/10.1116/1.585422

50. Tiggelaar RM, Berenschot JW, De Boer JH et al (2005) Fabrication and characterization of high-temperature microreactors with thin film heater and sensor patterns in silicon nitride tubes. Lab Chip 5:326-336. https://doi.org/10.1039/b414857f

51. Zhang M, Olson EA, Twesten RD et al (2005) In situ transmission electron microscopy studies enabled by microelectromechanical system technology. J Mater Res 20:1802-1807. https:// doi.org/10.1557/JMR.2005.0225

52. Spruit RG, Tijn Van Omme J, Ghatkesar MK, Hugo Pérez Garza $\mathrm{H}$ (2017) A review on development and optimization of microheaters for high-temperature in situ studies. J Microelectromechanical Syst 26:1165-1182. https://doi.org/10.1109/JMEMS .2017.2757402

53. Allard LF, Bigelow WC, Jose-Yacaman M et al (2009) A new MEMS-based system for ultra-high-resolution imaging at elevated temperatures. Microsc Res Tech 72:208-215. https://doi. org/10.1002/jemt.20673

54. Baker RTK (1979) In situ electron microscopy studies of catalyst particle behavior. Catal Rev 19:161-209. https://doi. org/10.1080/03602457908068055

55. Allard LF, Overbury SH, Bigelow WC et al (2012) Novel MEMSbased gas-cell/heating specimen holder provides advanced imaging capabilities for in situ reaction studies. Microsc Microanal 18:656-666. https://doi.org/10.1017/S1431927612001249

56. Giorgio S, Sao Joao S, Nitsche S et al (2006) Environmental electron microscopy (ETEM) for catalysts with a closed E-cell with carbon windows. Ultramicroscopy 106:503-507. https://doi. org/10.1016/j.ultramic.2006.01.006

57. Konishi H, Ishikawa A, Jiang Y-B et al (2003) Sealed environmental cell microscopy. Microsc Microanal 9:902-903. https:// doi.org/10.1017/s1431927603444516

58. Creemer JF, Helveg S, Hoveling GH et al (2008) Atomic-scale electron microscopy at ambient pressure. Ultramicroscopy 108:993-998. https://doi.org/10.1016/j.ultramic.2008.04.014

59. Creemer JF, Helveg S, Kooyman PJ et al (2010) A MEMS reactor for atomic-scale microscopy of nanomaterials under industrially relevant conditions. J Microelectromechanical Syst 19:254-264. https://doi.org/10.1109/JMEMS.2010.2041190 
60. Doll T, Hochberg M, Barsic D, Scherer A (2000) Micromachined electron transparent alumina vacuum windows. Sens Actuators A Phys 87:52-59. https://doi.org/10.1016/S0924 -4247(00)00461-1

61. Boyes ED, Gai PL (1997) Environmental high resolution electron microscopy and applications to chemical science. Ultramicroscopy 67:219-232. https://doi.org/10.1016/S0304-3991(96)00099 $-\mathrm{X}$

62. Sharma R, Crozier PA, Marx R, Weiss K (2003) An environmental transmission electron microscope for in-situ observation of chemical processes at the nanometer level. Microsc Microanal 9:912-913. https://doi.org/10.1017/s1431927603444565

63. Sharma R (2012) Experimental set up for in situ transmission electron microscopy observations of chemical processes. Micron 43:1147-1155. https://doi.org/10.1016/j.micron.2012.01.007

64. Ramade J, Langlois C, Pellarin M et al (2017) Tracking the restructuring of oxidized silver-indium nanoparticles under a reducing atmosphere by environmental HRTEM. Nanoscale 9:13563-13574. https://doi.org/10.1039/c7nr02986a

65. Boyes ED, Lagrow AP, Ward MR et al (2020) Single atom dynamics in chemical reactions. Acc Chem Res. https://doi. org/10.1021/acs.accounts.9b00500

66. Sharma R, Crozier PA (2005) Environmental transmission electron microscopy in nanotechnology. In: Yao N, Wang ZL (eds) Handbook of microscopy for nanotechnology. Springer, Boston, pp 531-565

67. Hansen TW, Wagner JB (2012) Environmental transmission electron microscopy in an aberration-corrected environment. Microsc Microanal 18:684-690. https://doi.org/10.1017/S1431 927612000293

68. Yoshida H, Kuwauchi Y, Jinschek JR et al (2012) Visualizing gas molecules interacting with supported nanoparticulate catalysts at reaction conditions. Science 80-(335):317-319. https://doi. org/10.1126/science. 1213194

69. Yaguchi T, Suzuki M, Watabe A et al (2011) Development of a high temperature-atmospheric pressure environmental cell for high-resolution TEM. J Electron Microsc (Tokyo) 60:217-225. https://doi.org/10.1093/jmicro/dfr011

70. El-Sayed MA (2001) Some interesting properties of metals confined in time and nanometer space of different shapes. Acc Chem Res 34:257-264. https://doi.org/10.1021/ar960016n

71. Jaeger NI (2001) Bridging gaps and opening windows. Science 80-(293):1601-1602. https://doi.org/10.1126/science.1064595

72. Topsøe H (2000) In situ characterization of catalysts. Stud Surf Sci Catal 130:1-21. https://doi.org/10.1016/s0167 -2991(00)80942-8

73. Topsøe H (2003) Developments in operando studies and in situ characterization of heterogeneous catalysts. J Catal 216:155-164. https://doi.org/10.1016/S0021-9517(02)00133-1

74. Hansen PL, Wagner JB, Helveg S et al (2002) Atom-resolved imaging of dynamic shape changes in supported copper nanocrystals. Science 80-(295):2053-2055. https://doi. org/10.1126/science. 1069325

75. Piccolo L (2020) Restructuring effects of the chemical environment in metal nanocatalysis and single-atom catalysis. Catal Today. https://doi.org/10.1016/j.cattod.2020.03.052

76. De Jonge N, Bigelow WC, Veith GM (2010) Atmospheric pressure scanning electron microscopy. Nano Lett 10:1028-1031. https://doi.org/10.1021/n1904254g

77. Zhang S, Plessow PN, Willis JJ et al (2016) Dynamical observation and detailed description of catalysts under strong metalsupport interaction. Nano Lett 16:4528-4534. https://doi. org/10.1021/acs.nanolett.6b01769

78. Zhang S, Chen C, Cargnello M et al (2015) Dynamic structural evolution of supported palladium-ceria core-shell catalysts revealed by in situ electron microscopy. Nat Commun 6:1-6. https://doi.org/10.1038/ncomms 8778

79. Dai S, You Y, Zhang S et al (2017) In situ atomic-scale observation of oxygen-driven core-shell formation in Pt3Co nanoparticles. Nat Commun. https://doi.org/10.1038/s41467-017-00161-y

80. Kawasaki T, Ueda K, Ichihashi M, Tanji T (2009) Improvement of windowed type environmental-cell transmission electron microscope for in situ observation of gas-solid interactions. Rev Sci Instrum. https://doi.org/10.1063/1.3250862

81. Creemer JF, Santagata F, Morana B, et al (2011) An all-in-one nanoreactor for high-resolution microscopy on nanomaterials at high pressures. In: 2011 IEEE 24th international conference on micro electro mechanical systems. IEEE, pp 1103-1106

82. Mehraeen S, McKeown JT, Deshmukh PV et al (2013) A (S) TEM gas cell holder with localized laser heating for in situ experiments. Microsc Microanal 19:470-478. https://doi.org/10.1017/ S1431927612014419

83. Yokosawa T, Alan T, Pandraud G et al (2012) In-situ TEM on (de)hydrogenation of $\mathrm{Pd}$ at $0.5-4.5$ bar hydrogen pressure and $20-400^{\circ} \mathrm{C}$. Ultramicroscopy $112: 47-52$. https://doi. org/10.1016/j.ultramic.2011.10.010

84. Pandraud G, Morana B, Wei J, Juffermans C (2016) 10 bar nanoreactors for in situ transmission electron microscopy. In: European Microscopy Congress 2016: Proceedings. Wiley-VCH Verlag GmbH \& Co. KGaA, pp 277-278

85. DENSsolutions DENS climate. https://denssolutions.com/produ cts/climate/

86. Song B, Yang TT, Yuan Y et al (2020) Revealing sintering kinetics of MoS 2 -supported metal nanocatalysts in atmospheric gas environments via operando transmission electron microscopy. ACS Nano 14:4074-4086. https://doi.org/10.1021/acsna no. $9 \mathrm{~b} 08757$

87. Erdamar AK, Malladi S, Tichelaar FD, Zandbergen HW (2016) Closed cell systems for in situ TEM with gas environments ranging from 0.1 to 5 bar. Controlled atmosphere transmission electron microscopy. Springer International Publishing, Cham, pp $165-210$

88. Masliuk L, Swoboda M, Algara-Siller G et al (2018) A quasi in situ TEM grid reactor for decoupling catalytic gas phase reactions and analysis. Ultramicroscopy 195:121-128. https://doi. org/10.1016/j.ultramic.2018.09.001

89. van Hoof AJF, van der Poll RCJ, Friedrich H, Hensen EJM (2020) Dynamics of silver particles during ethylene epoxidation. Appl Catal B Environ 272:118983. https://doi.org/10.1016/j. apcatb.2020.118983

90. Alan T, Yokosawa T, Gaspar J et al (2012) Micro-fabricated channel with ultra-thin yet ultra-strong windows enables electron microscopy under 4-bar pressure. Appl Phys Lett 100:081903. https://doi.org/10.1063/1.3688490

91. Vendelbo SB, Kooyman PJ, Creemer JF et al (2013) Method for local temperature measurement in a nanoreactor for in situ highresolution electron microscopy. Ultramicroscopy 133:72-79. https://doi.org/10.1016/j.ultramic.2013.04.004

92. Meirer F, Weckhuysen BM (2018) Spatial and temporal exploration of heterogeneous catalysts with synchrotron radiation. Nat Rev Mater 3:324-340. https://doi.org/10.1038/s4157 8-018-0044-5

93. De Smit E, Swart I, Creemer JF et al (2008) Nanoscale chemical imaging of a working catalyst by scanning transmission X-ray microscopy. Nature 456:222-225. https://doi.org/10.1038/natur $\mathrm{e} 07516$

94. Li Y, Zakharov D, Zhao S et al (2015) Complex structural dynamics of nanocatalysts revealed in Operando conditions by correlated imaging and spectroscopy probes. Nat Commun 6:7583. https://doi.org/10.1038/ncomms 8583 
95. Cats KH, Andrews JC, Stéphan O et al (2016) Active phase distribution changes within a catalyst particle during FischerTropsch synthesis as revealed by multi-scale microscopy. Catal Sci Technol 6:4438-4449. https://doi.org/10.1039/c5cy01524c

96. Xu M, Yao S, Rao D et al (2018) Insights into interfacial synergistic catalysis over $\mathrm{Ni} @ \mathrm{TiO} 2-\mathrm{x}$ catalyst toward water-gas shift reaction. J Am Chem Soc 140:11241-11251. https://doi. org $/ 10.1021 /$ jacs. $8 \mathrm{~b} 03117$

97. Resasco J, Dai S, Graham G et al (2018) Combining in-situ transmission electron microscopy and infrared spectroscopy for understanding dynamic and atomic-scale features of supported metal catalysts. J Phys Chem C 122:25143-25157. https://doi. org/10.1021/acs.jpcc.8b03959

98. Yoshida H, Matsuura K, Kuwauchi Y et al (2011) Temperature-dependent change in shape of platinum nanoparticles supported on $\mathrm{CeO} 2$ during catalytic reactions. Appl Phys Express 4:065001. https://doi.org/10.1143/APEX.4.065001

99. Altantzis T, Lobato I, De Backer A et al (2019) Three-dimensional quantification of the facet evolution of Pt nanoparticles in a variable gaseous environment. Nano Lett 19:477-481. https://doi.org/10.1021/acs.nanolett.8b04303

100. Tan SF, Chee SW, Baraissov Z et al (2019) Real-time imaging of nanoscale redox reactions over bimetallic nanoparticles. Adv Funct Mater 29:1-10. https://doi.org/10.1002/adfm.20190 3242

101. Avanesian T, Dai S, Kale MJ et al (2017) Quantitative and atomic-scale view of CO-induced Pt nanoparticle surface reconstruction at saturation coverage via DFT calculations coupled with in situ TEM and IR. J Am Chem Soc 139:4551-4558. https ://doi.org/10.1021/jacs.7b01081

102. Bahri M, Dembélé K, Sassoye C et al (2018) In situ insight into the unconventional ruthenium catalyzed growth of carbon nanostructures. Nanoscale 10:14957-14965. https://doi.org/10.1039/ c8nr01227j

103. Huang X, Farra R, Schlögl R, Willinger MG (2019) Growth and termination dynamics of multiwalled carbon nanotubes at near ambient pressure: an in situ transmission electron microscopy study. Nano Lett 19:5380-5387. https://doi.org/10.1021/acs. nanolett.9b01888

104. Beck A, Huang X, Artiglia L et al (2020) The dynamics of overlayer formation on catalyst nanoparticles and strong metal-support interaction. Nat Commun 11:1-40. https://doi.org/10.1038/ s41467-020-17070-2

105. Chee SW, Arce-Ramos JM, Li W et al (2020) Structural changes in noble metal nanoparticles during $\mathrm{CO}$ oxidation and their impact on catalyst activity. Nat Commun 11:1-9. https://doi. org/10.1038/s41467-020-16027-9

106. Plodinec M, Nerl HC, Farra R et al (2020) Versatile homebuilt gas feed and analysis system for operando TEM of catalysts at work. Microsc Microanal 26:220-228. https://doi.org/10.1017/ S143192762000015X

107. Crozier PA, Chenna S (2011) In situ analysis of gas composition by electron energy-loss spectroscopy for environmental transmission electron microscopy. Ultramicroscopy 111:177-185. https ://doi.org/10.1016/j.ultramic.2010.11.005

108. Chenna S, Crozier PA (2012) Operando transmission electron microscopy: a technique for detection of catalysis using electron energy-loss spectroscopy in the transmission electron microscope. ACS Catal 2:2395-2402. https://doi.org/10.1021/cs300 4853

109. Delariva AT, Hansen TW, Challa SR, Datye AK (2013) In situ transmission electron microscopy of catalyst sintering. J Catal 308:291-305. https://doi.org/10.1016/j.jcat.2013.08.018

110. Yu J, Yuan W, Yang H et al (2018) Fast gas-solid reaction kinetics of nanoparticles unveiled by millisecond in situ electron diffraction at ambient pressure. Angew Chem Int Ed 57:1134411348. https://doi.org/10.1002/anie.201806541

111. Zhou H, Zhao Y, Xu J et al (2020) Recover the activity of sintered supported catalysts by nitrogen-doped carbon atomization. Nat Commun. https://doi.org/10.1038/s41467-019-14223-w

112. Gaulandris F, Simonsen SB, Wagner JB et al (2020) Methods for calibration of specimen temperature during in situ transmission electron microscopy experiments. Microsc Microanal 26:3-17. https://doi.org/10.1017/S1431927619015344

113. Bataineh KM (2016) Developing of an environmental cell TEM holder for dynamic in situ observation. Rev Sci Instrum. https:// doi.org/10.1063/1.4942245

114. Vogel D, Spiel C, Suchorski Y et al (2011) Mapping the local reaction kinetics by PEEM: CO oxidation on individual (100)type grains of Pt foil. Surf Sci 605:1999-2005. https://doi. org/10.1016/j.susc.2011.07.018

115. Vogel D, Spiel C, Suchorski Y et al (2012) Local catalytic ignition during $\mathrm{CO}$ oxidation on low-index Pt and Pd surfaces: a combined PEEM, MS, and DFT study. Angew Chem Int Ed 51:10041-10044. https://doi.org/10.1002/anie.201204031

116. Williamson MJ, Tromp RM, Vereecken PM et al (2003) Dynamic microscopy of nanoscale cluster growth at the solid-liquid interface. Nat Mater 2:532-536. https://doi.org/10.1038/nmat944

117. Ross FM (2015) Opportunities and challenges in liquid cell electron microscopy. Science 80(350):6267. https://doi.org/10.1126/ science.aaa9886

118. de Jonge N, Houben L, Dunin-Borkowski RE, Ross FM (2019) Resolution and aberration correction in liquid cell transmission electron microscopy. Nat Rev Mater 4:61-78. https://doi. org/10.1038/s41578-018-0071-2

119. Jonge N, Ross F (2011) Electron microscopy of specimens in liquid. Nat Nanotechnol 6:695-704. https://doi.org/10.1038/nnano .2011 .161

120. Zhu GZ, Prabhudev S, Yang J et al (2014) In situ liquid cell TEM study of morphological evolution and degradation of Pt-Fe nanocatalysts during potential cycling. J Phys Chem C 118:2211122119. https://doi.org/10.1021/jp506857b

121. Zheng H, Smith RK, Jun YW et al (2009) Observation of single colloidal platinum nanocrystal growth trajectories. Science 80-(324):1309-1312. https://doi.org/10.1126/science.1172104

122. Murray CB (2009) Watching nanocrystals grow. Science 80-(324):1276-1277. https://doi.org/10.1126/science.1174666

123. Schneider NM, Norton MM, Mendel BJ et al (2014) Electron-water interactions and implications for liquid cell electron microscopy. J Phys Chem C 118:22373-22382. https://doi. org/10.1021/jp507400n

124. Wang M, Park C, Woehl TJ (2018) Quantifying the nucleation and growth kinetics of electron beam nanochemistry with liquid cell scanning transmission electron microscopy. Chem Mater 30:7727-7736. https://doi.org/10.1021/acs.chemmater.8b03050

125. Thiberge S, Nechushtan A, Sprinzak D et al (2004) Scanning electron microscopy of cells and tissues under fully hydrated conditions. Proc Natl Acad Sci USA 101:3346-3351. https://doi. org/10.1073/pnas.0400088101

126. de Jonge N, Peckys DB, Kremers GJ, Piston DW (2009) Electron microscopy of whole cells in liquid with nanometer resolution. Proc Natl Acad Sci USA 106:2159-2164

127. Ring EA, De Jonge N (2010) Microfluidic system for transmission electron microscopy. Microsc Microanal 16:622-629. https ://doi.org/10.1017/S1431927610093669

128. Verpoorte E, De Rooij NF (2003) Microfluidics meets MEMS. In: Proceedings of the IEEE. Institute of Electrical and Electronics Engineers Inc., pp 930-953

129. Yesibolati MN, Mortensen KI, Sun H et al (2020) Unhindered brownian motion of individual nanoparticles in liquid-phase 
scanning transmission electron microscopy. Nano Lett 20:71087115. https://doi.org/10.1021/acs.nanolett.0c02352

130. Leenheer AJ, Sullivan JP, Shaw MJ, Harris CT (2015) A sealed liquid cell for in situ transmission electron microscopy of controlled electrochemical processes. J Microelectromechanical Syst 24:1061-1068. https://doi.org/10.1109/JMEMS.2014.2380771

131. Leenheer AJ, Jungjohann KL, Thomas Harris C (2015) Design of a heated liquid cell for in-situ transmission electron microscopy. Microsc Microanal 21:1293-1294. https://doi.org/10.1017/s1431 927615007254

132. Li D, Nielsen MH, Lee JRI et al (2012) Direction-specific interactions control crystal growth by oriented attachment. Science 80-(336):1014-1018. https://doi.org/10.1126/science.1219643

133. Tanase M, Winterstein J, Sharma R et al (2015) High-resolution imaging and spectroscopy at high pressure: a novel liquid cell for the transmission electron microscope. Microsc Microanal 21:1629-1638. https://doi.org/10.1017/S1431927615015482

134. Mehdi BL, Qian J, Nasybulin E et al (2015) Observation and quantification of nanoscale processes in lithium batteries by operando electrochemical (S)TEM. Nano Lett 15:2168-2173. https://doi.org/10.1021/acs.nanolett.5b00175

135. Mayrhofer KJJ, Meier JC, Ashton SJ et al (2008) Fuel cell catalyst degradation on the nanoscale. Electrochem commun 10:1144-1147. https://doi.org/10.1016/j.elecom.2008.05.032

136. Hodnik N, Cherevko S (2019) Spot the difference at the nanoscale: identical location electron microscopy in electrocatalysis. Curr Opin Electrochem 15:73-82. https://doi.org/10.1016/j. coelec.2019.03.007

137. Jungjohann KL, Bliznakov S, Sutter PW et al (2013) In situ liquid cell electron microscopy of the solution growth of $\mathrm{Au}-\mathrm{Pd}$ core-shell nanostructures. Nano Lett 13:2964-2970. https://doi. org/10.1021/nl4014277

138. Beermann V, Holtz ME, Padgett E et al (2019) Real-time imaging of activation and degradation of carbon supported octahedral Pt-Ni alloy fuel cell catalysts at the nanoscale using: In situ electrochemical liquid cell STEM. Energy Environ Sci 12:24762485. https://doi.org/10.1039/c9ee01185d

139. Fan K, Zou H, Lu Y et al (2018) Direct observation of structural evolution of metal chalcogenide in electrocatalytic water oxidation. ACS Nano 12:12369-12379. https://doi.org/10.1021/acsna no. 8 b06312

140. Ortiz Peña N, Ihiawakrim D, Han M et al (2019) Morphological and structural evolution of $\mathrm{Co} 3 \mathrm{O} 4$ nanoparticles revealed by in situ electrochemical transmission electron microscopy during electrocatalytic water oxidation. ACS Nano 13:11372-11381. https://doi.org/10.1021/acsnano.9b04745

141. Abidi W, Remita H (2011) Gold based nanoparticles generated by radiolytic and photolytic methods. Recent Patents Eng 4:170 188. https://doi.org/10.2174/187221210794578556

142. Evans JE, Jungjohann KL, Browning ND, Arslan I (2011) Controlled growth of nanoparticles from solution with in situ liquid transmission electron microscopy. Nano Lett 11:2809-2813. https://doi.org/10.1021/nl201166k

143. Woehl TJ, Evans JE, Arslan I et al (2012) Direct in situ determination of the mechanisms controlling nanoparticle nucleation and growth. ACS Nano 6:8599-8610. https://doi.org/10.1021/nn303 $371 \mathrm{y}$

144. Holtz ME, Yu Y, Gao J et al (2013) In situ electron energy-loss spectroscopy in liquids. Microsc Microanal 19:1027-1035. https ://doi.org/10.1017/S1431927613001505

145. Lewis EA, Haigh SJ, Slater TJA et al (2014) Real-time imaging and local elemental analysis of nanostructures in liquids. Chem Commun 50:10019-10022. https://doi.org/10.1039/c4cc02743d

146. Malis T, Cheng SC, Egerton RF (1988) EELS log-ratio technique for specimen-thickness measurement in the TEM. J Electron
Microsc Tech 8:193-200. https://doi.org/10.1002/jemt.10600 80206

147. Algara-Siller G, Lehtinen O, Wang FC et al (2015) Square ice in graphene nanocapillaries. Nature 519:443-445. https://doi. org/10.1038/nature14295

148. Kelly DJ, Zhou M, Clark N et al (2018) Nanometer resolution elemental mapping in graphene-based TEM liquid cells. Nano Lett 18:1168-1174. https://doi.org/10.1021/acs.nanolett.7b047 13

149. Schneider NM (2016) Electron beam effects in liquid cell TEM and STEM. Liquid cell electron microscopy. Cambridge University Press, Cambridge, pp 140-163

150. Rehn SM, Jones MR (2018) New strategies for probing energy systems with in situ liquid-phase transmission electron microscopy. ACS Energy Lett 3:1269-1278. https://doi.org/10.1021/ acsenergylett.8b00527

151. Grogan JM, Rotkina L, Bau HH (2011) In situ liquid-cell electron microscopy of colloid aggregation and growth dynamics. Phys Rev E 83:061405. https://doi.org/10.1103/PhysRevE.83.061405

152. Grogan JM, Schneider NM, Ross FM, Bau HH (2014) Bubble and pattern formation in liquid induced by an electron beam. Nano Lett 14:359-364. https://doi.org/10.1021/n1404169a

153. Lu Y, Yin WJ, Peng KL et al (2018) Self-hydrogenated shell promoting photocatalytic $\mathrm{H} 2$ evolution on anatase $\mathrm{TiO} 2$. Nat Commun. https://doi.org/10.1038/s41467-018-05144-1

154. Wu F, Yao N (2015b) Advances in sealed liquid cells for insitu TEM electrochemial investigation of lithium-ion battery. Nano Energy 11:196-210. https://doi.org/10.1016/j.nanoe n.2014.11.004

155. Buban JP, Ramasse Q, Gipson B et al (2010) High-resolution low-dose scanning transmission electron microscopy. J Electron Microsc (Tokyo) 59:103-112. https://doi.org/10.1093/jmicro/ dfp052

156. Krivanek OL, Dellby N, Murfitt MF et al (2010) Gentle STEM: ADF imaging and EELS at low primary energies. Ultramicroscopy 110:935-945. https://doi.org/10.1016/J.ULTRA MIC.2010.02.007

157. Miller BK, Barker TM, Crozier PA (2015) Novel sample preparation for operando TEM of catalysts. Ultramicroscopy 156:18-22. https://doi.org/10.1016/j.ultramic.2015.05.003

158. Santos Aires FJC, Bertolini JC (2009) On the use of silicon nitride in catalysis. Top Catal 52:1492-1505. https://doi. org/10.1007/s11244-009-9296-Z

159. Kim H-E, Moorhead AJ (1990) High-temperature gaseous corrosion of Si3N4 in $\mathrm{H} 2-\mathrm{H} 2 \mathrm{O}$ and $\mathrm{Ar}-\mathrm{O} 2$ environments. J Am Ceram Soc 73:3007-3014. https://doi.org/10.1111/j.1151-2916.1990. tb06708.x

160. Munro RG, Dapkunas SJ (1993) Corrosion characteristics of silicon carbide and silicon nitride. J Res 98:607-631. https:// doi.org/10.6028/jres.098.040

161. Textor M, de Jonge N (2018) Strategies for preparing graphene liquid cells for transmission electron microscopy. Nano Lett 18:3313-3321. https://doi.org/10.1021/acs.nanolett.8b01366

162. Kühne M, Börrnert F, Fecher S et al (2018) Reversible superdense ordering of lithium between two graphene sheets. Nature. https://doi.org/10.1038/s41586-018-0754-2

163. Monnet F, Schuurman Y, Cadete Santos Aires F et al (2001) Silicon nitride supported platinum catalysts for the partial oxidation of methane at high temperatures. Catal Today 64:51-58. https:// doi.org/10.1016/S0920-5861(00)00508-3

164. Hullmann D, Wendt G, Šingliar U, Ziegenbalg G (2002) Propane dehydrogenation over supported platinum silicon nitride catalysts. Appl Catal A Gen 225:261-270. https://doi.org/10.1016/ S0926-860X(01)00871-7 
165. Claassen WAP, Valkenburg WGJN, Habraken FHPM, Tamminga Y (1983) Characterization of plasma silicon nitride layers. J Electrochem Soc 130:2419-2423. https://doi.org/10.1149/1.2119600

166. French PJ, Sarro PM, Mallée R et al (1997) Optimization of a low-stress silicon nitride process for surface-micromachining applications. Sens Actuators A Phys 58:149-157. https://doi. org/10.1016/S0924-4247(96)01397-0

167. Zaluzec NJ (2015) When is Si3N4 not Si3N4? When it is a low stress SiNx membrane window. Microsc Microanal 21:959-960. https://doi.org/10.1017/s1431927615005590

168. Du H (1989) Oxidation studies of crystalline CVD silicon nitride. J Electrochem Soc 136:1527. https://doi.org/10.1149/1.2096955

169. Simonsen SB, Chorkendorff I, Dahl S et al (2010) Direct observations of oxygen-induced platinum nanoparticle ripening studied by in situ TEM. J Am Chem Soc 132:7968-7975. https://doi. org/10.1021/ja910094r

170. Xin HL, Niu K-Y, Alsem DH, Zheng H (2013) In situ TEM study of catalytic nanoparticle reactions in atmospheric pressure gas environment. Microsc Microanal 19:1558-1568. https://doi. org/10.1017/S1431927613013433

171. Protochips Incorporated (2020) Protochips atmosphere. https:// www.protochips.com/products/atmosphere/
172. Miller BK, Crozier PA (2014) Analysis of catalytic gas products using electron energy-loss spectroscopy and residual gas analysis for operando transmission electron microscopy. Microsc Microanal 20:815-824. https://doi.org/10.1017/S1431927614000749

173. Meti S, Balavald KB, Sheeparmatti BG (2016) MEMS piezoresistive pressure sensor : a survey. Int J Engin Res App 6:23-31

174. Khan MI, Mukherjee K, Shoukat R, Dong H (2017) A review on $\mathrm{pH}$ sensitive materials for sensors and detection methods. Microsyst Technol 23:4391-4404. https://doi.org/10.1007/s0054 2-017-3495-5

175. Wood PM (1988) The potential diagram for oxygen at $\mathrm{pH} 7$. Biochem J 253:287-289. https://doi.org/10.1042/bj2530287

176. Schlögl R (2015) Heterogeneous catalysis. Angew Chem Int Ed 54:3465-3520. https://doi.org/10.1002/anie.201410738

Publisher's Note Springer Nature remains neutral with regard to jurisdictional claims in published maps and institutional affiliations. 